\title{
C1q binding to surface-bound IgG is stabilized by $\mathrm{C1}_{2} \mathrm{~s}_{2}$ proteases
}

Seline A. Zwarthoff ${ }^{1}$, Kevin Widmer $^{2}$, Annemarie Kuipers ${ }^{1}$, Jürgen Strasser ${ }^{3}$, Maartje Ruyken $^{1}$, Piet C. Aerts ${ }^{1}$, Carla J.C. de Haas ${ }^{1}$, Deniz Ugurlar ${ }^{4}$, Gestur Vidarsson ${ }^{5}$, Jos A. G. Van Strijp$^{1}$, Piet Gros ${ }^{4}$, Paul W.H.I. Parren ${ }^{6,7}$, Kok P.M. van Kessel ${ }^{1}$, Johannes Preiner ${ }^{3}$, Frank J. Beurskens $^{8}$, Janine Schuurman ${ }^{8}$, Daniel Ricklin², Suzan H.M. Rooijakkers ${ }^{1}$

${ }^{1}$ Medical Microbiology, University Medical Center Utrecht, Utrecht University, Utrecht, The Netherlands;

${ }^{2}$ Pharmaceutical Sciences, University of Basel, Basel, Switzerland;

${ }^{3}$ University of Applied Sciences Upper Austria, 4020 Linz, Austria;

${ }^{4}$ Crystal and Structural Chemistry, Utrecht University, Utrecht, The Netherlands;

${ }^{5}$ Experimental Immunohematology, Sanquin Research, Amsterdam, The Netherlands

${ }^{6}$ Immunohematology and Blood Transfusion, Leiden University Medical Center, Leiden, The Netherlands.

${ }^{7}$ Lava Therapeutics, Utrecht, The Netherlands

${ }^{8}$ Genmab, Utrecht, The Netherlands;

\section{Running title: $\mathrm{Cl}_{2} \mathrm{~s}_{2}$ enhance stability of C1q-IgG}




\begin{abstract}
Complement is an important effector mechanism for antibody-mediated clearance of infections and tumor cells. Upon binding to target cells, the antibody's constant $(\mathrm{Fc})$ domain recruits complement component $\mathrm{C} 1$ to initiate a proteolytic cascade that generates lytic pores and stimulates phagocytosis. The $\mathrm{C} 1$ complex $\left(\mathrm{Clqr}_{2} \mathrm{~s}_{2}\right)$ consists of the large recognition protein $\mathrm{C} 1 \mathrm{q}$ and a heterotetramer of proteases $\mathrm{C} 1 \mathrm{r}$ and $\mathrm{C} 1 \mathrm{~s}\left(\mathrm{C}_{1} \mathrm{r}_{2} \mathrm{~s}_{2}\right)$. While interactions between $\mathrm{C} 1$ and IgG-Fc's are believed to be mediated by the globular heads of C1q, we here find that $\mathrm{C}_{1} \mathrm{r}_{2} \mathrm{~s}_{2}$ proteases affect the capacity of $\mathrm{C} 1 \mathrm{q}$ to form an avid complex with surface-bound IgG molecules (on various DNP-coated surfaces and pathogenic Staphylococcus aureus). The extent to which $\mathrm{C}_{1} \mathrm{r}_{2} \mathrm{~s}_{2}$ contribute to $\mathrm{C} 1 \mathrm{q}-\mathrm{IgG}$ stability strongly differs between human $\mathrm{IgG}$ subclasses. Using antibody engineering of monoclonal $\mathrm{IgG}$ we reveal that hexamer-enhancing mutations improve $\mathrm{C} 1 \mathrm{q}-\mathrm{IgG}$ stability, both in absence and presence of $\mathrm{C}_{1} \mathrm{r}_{2} \mathrm{~s}_{2}$. In addition, hexamer-enhanced IgGs targeting $S$. aureus mediate improved complement-dependent phagocytosis by human neutrophils. Altogether, these molecular insights into complement binding to surface-bound IgGs could be important for optimal design of antibody therapies.
\end{abstract}




\section{Introduction}

Antibodies are important mediators of the human complement response, which offers critical protection against microbial infections and damaged host cells ${ }^{1}$. In order to initiate a complement response, an antibody molecule first needs to bind antigens on the target cell via its antigen-binding ( $\mathrm{Fab})$ domains ${ }^{2-5}$. Subsequently, the antibody's constant $(\mathrm{Fc})$ domain recruits the first complement protein complex, $\mathrm{C} 1$, to the cell surface (SFig. 1A). The large $\mathrm{C} 1$

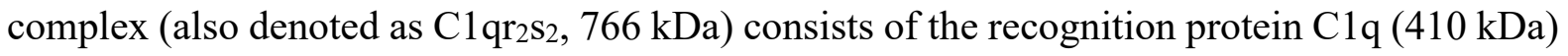
and a heterotetramer of serine proteases $\mathrm{C} 1 \mathrm{r}$ and $\mathrm{C} 1 \mathrm{~s}$ (denoted $\mathrm{C}_{2} \mathrm{r}_{2} \mathrm{~s}_{2}, 356 \mathrm{kDa}$ ) (SFig. 1B). While $\mathrm{C} 1 \mathrm{q}$ is responsible for antibody recognition, its attached proteases $\mathrm{C}_{1} \mathrm{r}_{2} \mathrm{~s}_{2}$ induce the activation of downstream enzymatic complexes, i.e. $\mathrm{C} 3$ convertases $\left(\mathrm{C} 4 \mathrm{~b} 2 \mathrm{~b}{ }^{6}\right)$, that catalyze the covalent deposition of $\mathrm{C} 3$-derived molecules (e.g. C3b and its degradation product iC $3 b$ ) onto the target cell surface (SFig. 1A) ${ }^{7,8}$. C3b opsonizes the target cell surface and can induce formation of lytic pores (membrane attack complex: MAC) in the target cell membrane ${ }^{9-11}$. In contrast to human cells and Gram-negative bacteria, Gram-positive bacteria are not susceptible to the MAC due to their thick cell wall ${ }^{12}$. On these bacteria, efficient decoration with $\mathrm{C} 3 \mathrm{~b}$ and $\mathrm{iC} 3 \mathrm{~b}$ is essential for triggering effective phagocytic uptake of target cells via complement receptors (CR) expressed on phagocytes of which the integrin CR3 (also denoted $\mathrm{CD} 11 \mathrm{~b} / \mathrm{CD} 18$ ) is considered most important ${ }^{13,14}$.

In recent years, our insights into IgG-dependent complement activation have increased significantly. A combination of structural, biophysical and functional studies revealed that surface-bound IgG molecules (after Fab-mediated antigen binding) require organization into higher ordered structures, namely hexamers, to induce complement activation most effectively 15-19. Hexamerized IgGs are being held together by non-covalent Fc-Fc interactions and form an optimal platform for C1q docking (SFig. 1A). C1q has a 'bunch of tulips'-like structure, consisting of six collagen arms that each end in a globular (gC1q) domain (SFig. 1B) that binds the $\mathrm{Fc}$ region of an $\mathrm{IgG}$. As the affinity of $\mathrm{Clq}$ for a single $\mathrm{IgG}$ is very weak ${ }^{20,21}$, avidity achieved through simultaneous binding of all six globular domains to six oligomerized IgG molecules is paramount for a strong response ${ }^{15,17-19}$. Furthermore, it was found that $\operatorname{IgG}$ hexamerization could be manipulated by specific point mutations in the Fc-Fc contact region that enhance such oligomerization ${ }^{15,18,22}$. While these hexamer-enhancing mutations in IgG potentiate the efficacy of MAC-dependent cytotoxicity on tumor cells and Gram-negative bacteria ${ }^{15,23}$, their effect on complement-dependent phagocytosis is not known.

Because complement is an important effector mechanism to kill bacteria and tumor cells, development of complement-enhancing antibodies represents an attractive strategy for immune therapies ${ }^{1,24}$. Immunotherapy based on human monoclonal antibodies is not yet available for bacterial infections ${ }^{25-28}$. Such developments are mainly hampered by the fact that little is known about the basic mechanisms of complement activation on bacterial cells. For instance, we do not understand why certain antibodies induce complement activation on bacteria and others do not. In this study we set-out to investigate how antibacterial IgGs induce an effective complement response. By surprise, we noticed that $\mathrm{C} 1 \mathrm{q}-\mathrm{IgG}$ stability differs between human IgG subclasses. More detailed molecular investigations revealed that $\mathrm{C}_{1} \mathrm{r}_{2} \mathrm{~S}_{2}$ proteases are important for generating stable $\mathrm{C} 1 \mathrm{q}-\mathrm{IgG}$ complexes on various target surfaces. Furthermore, we demonstrate that $\mathrm{C} 1 \mathrm{q}-\mathrm{IgG}$ stability is influenced by antibody oligomerization. These 
molecular insights into $\mathrm{C} 1 \mathrm{q}$ binding to surface-bound IgGs may pave the way for optimal design of antibody therapies.

\section{Results}

\section{IgG-mediated complement activation does not always correlate with detection of C1q}

To enhance our understanding of complement activation by antibacterial IgGs, we studied complement activation by monoclonal antibodies against Staphylococcus aureus, an important Gram-positive pathogen and the leading cause of hospital-acquired infections. We generated IgGs against wall teichoic acid (WTA), a highly abundant and immunogenic cell wall glycopolymer that comprises $40 \%$ of the staphylococcal cell wall ${ }^{29-31}$. The variable domains of anti-WTA IgG1 $4497^{31}$ were cloned into HEK expression vectors encoding IgG1, IgG2, IgG3 and IgG4 Fc backbones. We included all IgG subclasses to obtain a better understanding of their variable complement effector functions ${ }^{1,32}$. After confirming that all IgG subclasses bound similarly to the bacterial surface (SFig. 2), we examined complement activation by antiWTA IgGs by incubating $S$. aureus with human serum as a complement source. To exclude involvement of naturally occurring anti-staphylococcal IgGs, we used serum that is depleted of natural $\operatorname{IgG}$ and $\operatorname{IgM}(\Delta \operatorname{IgG} \Delta \operatorname{IgM} \text { serum })^{33}$. Complement activation was first quantified by measuring deposition of $\mathrm{C} 3$ cleavage products on the surface of $S$. aureus using flow cytometry (Fig. 1A). In line with recent results, IgG1 and IgG3 antibodies against WTA elicit effective $\mathrm{C} 3 \mathrm{~b}$ deposition on $S$. aureus (Fig. 1A) ${ }^{34}$. Furthermore, IgG4 did not activate complement on $S$. aureus (Fig. 1A), which was expected because IgG4 has a reduced capability to interact with C1q ${ }^{35-37,38-41}$.

Our particular interest was in IgG2, which is the predominant IgG subclass against WTA in a natural human immune response ${ }^{30,42}$. Although $\operatorname{IgG} 2$ is often described as a poor complement activator, we here observed that anti-WTA IgG2 effectively induced C3b deposition on $S$. aureus, to a level that was comparable to anti-WTA IgG1 and IgG3 (Fig. 1A). These data support previous studies suggesting that $\operatorname{IgG} 2$ can activate complement when reacting with highly dense epitopes ${ }^{42-45}$.

When we took a closer look at different complement activation steps, we noticed an unexpected disparity between surface detection of $\mathrm{C} 3 \mathrm{~b}$ and $\mathrm{C} 1 \mathrm{q}$ for $\mathrm{IgG} 2$. While recruitment of $\mathrm{C} 1 \mathrm{q}$ is a prerequisite to initiate antibody-dependent complement activation, we observed that detection of $\mathrm{Clq}$ molecules on IgG2-coated bacteria was low compared to IgG1 and IgG3 (Fig. 1B). This was surprising because $\mathrm{C} 3 \mathrm{~b}$ deposition via these subclasses was similar (Fig. 1A). Using a monoclonal antibody that prevents $\mathrm{C} 1 \mathrm{q}-\mathrm{IgG}$ interactions ${ }^{46}$, we showed that $\mathrm{C} 3 \mathrm{~b}$ deposition via $\mathrm{IgG} 2$ was driven by $\mathrm{C} 1$ (SFig. 3). Also, inhibition of $\mathrm{C} 1$ via a bacterial protein that blocks C1r (BBK32 ${ }^{47-49}$ ) confirmed that $\mathrm{C} 1$ is required to deposit C3b onto IgG2-coated bacteria (SFig. 3). Furthermore, we showed that $\mathrm{C} 3 \mathrm{~b}$ molecules deposited by anti-WTA IgG2 antibodies are functional. We studied phagocytosis of bacteria by human neutrophils, the primary mechanism for elimination of $S$. aureus ${ }^{50}$. Although anti-WTA IgG2 did not potently induce Fc receptor-mediated phagocytosis of $S$. aureus (as expected from the predicted low 
affinity of IgG2 for Fc $\gamma \mathrm{R}^{32}$ ), we found that addition of complement strongly promoted the phagocytic uptake of IgG2-labelled S. aureus (Fig. 1C).

We wondered whether these findings could be translated to IgGs recognizing a different antigenic surface. To study this, we used an assay system in which beads are coupled with the model antigen 2,4-dinitrophenol (DNP) ${ }^{51}$ and coated with human IgGs specific for DNP (SFig. 4A-C) ${ }^{52}$. To mimic the highly abundant nature of WTA, beads were coated with saturating levels of DNP (quantified by measuring IgG binding using flow cytometry) (SFig. 4B). In accordance with our findings on $S$. aureus, we found that anti-DNP antibodies of the IgG1, IgG2 and IgG3 subclasses all potently induced a complement response and deposit $\mathrm{C} 3 \mathrm{~b}$ molecules onto the surface of DNP-beads (Fig. 1D). Again, whereas C3b opsonization could be correlated with the presence of $\mathrm{C} 1 \mathrm{q}$ on beads coated with IgG1 and IgG3, almost no C1q could be detected on the IgG2-coated surface (Fig. 1E).

In conclusion, on two independent surfaces, we showed that IgG1, IgG2 and IgG3 can all potently elicit $\mathrm{C} 1$-dependent deposition of $\mathrm{C} 3 \mathrm{~b}$ molecules. However, for IgG2 our data revealed an unexpected disparity between the detection of $\mathrm{C} 1 \mathrm{q}$ and downstream deposition of C3b molecules.

\section{$\mathrm{Clr}_{2} \mathrm{~s}_{2}$ proteases enhance the binding of C1q to target-bound IgG}

To better understand the above findings, we more closely examined the molecular interactions between $\mathrm{Clq}$ and target-bound IgGs by using purified $\mathrm{C} 1$ complexes. We included two forms of $\mathrm{C} 1 \mathrm{q}$ in our analyses: 1) $\mathrm{C} 1 \mathrm{q}$ in complex with $\mathrm{C}_{1} \mathrm{r}_{2} \mathrm{~S}_{2}$ proteases (denoted $\mathrm{C} 1$ ), which is representative for circulating $\mathrm{C} 1$ complexes in human blood ${ }^{53,54}$; or 2) recognition molecule C1q without proteases (denoted C1q) (Fig. 2A). When we studied binding of different forms of C1q to anti-DNP antibodies on DNP-beads, we noticed a discrepancy between the binding of non-complexed C1q molecules versus C1 (Fig. 2B, SFig. 4D). Particularly in the case of $\mathrm{IgG} 2$, we observed that binding of $\mathrm{C} 1$ was more efficient than binding of non-complexed $\mathrm{C} 1 \mathrm{q}$, as quantified by flow cytometric detection of surface-bound C1q (Fig. 2B). Western blotting was used to confirm that the different levels of $\mathrm{Clq}$ detected in flow cytometry actually represent different quantities of surface-bound C1q (SFig. 4E). When C1 complexes were dissociated by EDTA, which disrupts the calcium-dependent attachment of $\mathrm{C}_{1} \mathrm{r}_{2} \mathrm{~S}_{2}$ to $\mathrm{C} 1 \mathrm{q}^{55,56}$, binding was similar to $\mathrm{C} 1 \mathrm{q}$ alone (Fig. 2B). On IgG1-coated beads, we observed that $\mathrm{C}_{1} \mathrm{r}_{2} \mathrm{~s}_{2}$ proteases had subtle effect on binding of C1q (Fig. 2B). Furthermore, $\mathrm{C}_{1} \mathrm{r}_{2} \mathrm{~S}_{2}$ proteases had a very limited effect on the binding of C1q to IgG3 (Fig. 2B). Similar to these results on beads, we observed that EDTA reduced binding of purified $\mathrm{C} 1$ to $S$. aureus labelled with IgG1 and IgG2, while binding to IgG3 was much less affected (SFig. 5). Altogether, these studies suggest that attached $\mathrm{C}_{1} \mathrm{r}_{2} \mathrm{~S}_{2}$ proteases affect $\mathrm{C} 1 \mathrm{q}-\mathrm{IgG}$ interactions in a subclass-dependent manner. This finding is unexpected when considering that the direct interactions between $\mathrm{C} 1$ and $\operatorname{IgG}$ were shown to solely depend on the $\mathrm{gClq}$ domains ${ }^{16}$.

Since the surface density of antigens was earlier proposed to be a critical parameter for IgGmediated complement activation ${ }^{57-59}$, we wondered whether $\mathrm{C}_{1} \mathrm{r}_{2} \mathrm{~S}_{2}$ proteases also affect $\mathrm{C} 1 \mathrm{q}-$ IgG interactions at lower antigen concentrations. In the bead system, we lowered the DNP 
concentration by $\sim 300$-fold. At this lower DNP concentrations, we found that IgG3 was the most potent subclass triggering complement activation in human serum (SFig. 6) and that C3b deposition by IgG1 and IgG2 was inefficient. This corresponds with the idea that IgG3 more potently drives complement activation on low abundant antigens (presumably because it has a longer hinge region ${ }^{21,57,58,60}$ ). Upon studying binding of purified $\mathrm{C} 1$ complexes, we observed that $\mathrm{C}_{1} \mathrm{r}_{2} \mathrm{~S}_{2}$ proteases can also affect $\mathrm{C} 1 \mathrm{q}$ binding to $\mathrm{IgG} 3$ on beads with a lower DNP concentration. First, we observed that $\mathrm{C} 1$ bound more efficiently to IgG3 than non-complexed $\mathrm{Clq}$ (Fig. 2C). Also, disruption of $\mathrm{C} 1$ with EDTA caused an almost complete reduction of $\mathrm{C} 1 \mathrm{q}$ binding to IgG3 (Fig. 2C).

Altogether this suggests that $\mathrm{C}_{1} \mathrm{r}_{2} \mathrm{~S}_{2}$ proteases can enhance binding of $\mathrm{C} 1 \mathrm{q}$ to all IgG subclasses. However, the extent to which $\mathrm{C}_{1} \mathrm{r}_{2} \mathrm{~s}_{2}$ proteases contribute to $\mathrm{C} 1 \mathrm{q}$ binding depends both on the IgG subclass and antigen concentration.

\section{$\mathrm{Clr}_{2} \mathrm{~s}_{2}$ proteases enhance the stability of surface-bound C1q-IgG complexes}

To corroborate these results, we employed surface plasmon resonance (SPR) as an orthogonal technique to confirm the binding profiles and obtain dynamic information about the formation and stability of C1q-IgG complexes (Fig. 3A, SFig. 7). Using a flat DNP-labelled surface, prepared by coupling DNP-PEG-NHS to an activated carboxyl sensor chip (SFig. 7A), monoclonal anti-DNP antibodies could be captured at high density and stability (SFig. 7B). No binding was observed on a MeO-PEG-NHS surface that was used as a reference (SFig. 7C). By injecting either $\mathrm{C} 1 \mathrm{q}$ or $\mathrm{C} 1$ for 60 seconds, the assembly (during injection) and stability of $\mathrm{C} 1 \mathrm{q}-\mathrm{IgG} / \mathrm{C} 1-\mathrm{IgG}$ complexes (during the dissociation period) could be monitored over time. SPR analysis indeed confirmed that $\mathrm{C}_{1} \mathrm{r}_{2} \mathrm{~S}_{2}$ proteases affect the stability of $\mathrm{C} 1 \mathrm{q}-\mathrm{IgG}$ complexes, especially for IgG1 and IgG2 (Fig. 3A). Whereas both $\mathrm{C} 1 \mathrm{q}$ and $\mathrm{C} 1$ bound to the IgG1- and $\mathrm{IgG} 2$-coated sensor chips during protein injection, $\mathrm{C} 1$ dissociated much slower than $\mathrm{C} 1 \mathrm{q}$ after the injection was stopped, which suggests that $\mathrm{C} 1$ forms more stable interactions with the antibody-coated surface. Additionally, we observed a weaker association of $\mathrm{C} 1 \mathrm{q}$ in absence of $\mathrm{C}_{1} \mathrm{r}_{2} \mathrm{~S}_{2}$ to IgG2-coated chips during the injection (Fig. 3A). In line with our studies on IgG3labelled beads, $\mathrm{C}_{1} \mathrm{r}_{2} \mathrm{~s}_{2}$ proteases did not notably affect $\mathrm{C} 1 \mathrm{q}$ binding to IgG3-coated chips. However, SPR experiments showed that $\mathrm{C}_{1} \mathrm{r}_{2} \mathrm{~S}_{2}$ proteases had a more pronounced impact on binding of $\mathrm{Clq}$ when the IgG3 capturing concentration was lowered 5-fold (SFig. 7D). As expected, neither $\mathrm{C} 1 \mathrm{q}$ nor $\mathrm{C} 1$ showed detectable binding to IgG4.

To directly visualize $\mathrm{C} 1 \mathrm{q}-\mathrm{IgG}$ complexes, we performed high-speed atomic force microscopy (HS-AFM) experiments. To enable reliable identification of C1q-IgG complexes in HS-AFM, we employed the anti-DNP triple mutant (IgG1-E345R, E430G, and S440Y, denoted IgG1RGY), which was shown to efficiently associate into IgG1 hexamers in solution ${ }^{19,61}$. DNPlabelled supported lipid bilayers were therefore pre-incubated with anti-DNP IgG1-RGY ${ }^{17}$. Then, C1q or C1 was added and the resulting complexes where visualized via HS-AFM (Fig. 3B, Movies S1 and S2). While the complexes of C1 that bound to the IgG1-RGY hexamers were not significantly disturbed by the minimal forces exerted by the HS-AFM tip, C1q alone was frequently removed from the IgG1-RGY hexamers as a result of the tip-sample interaction under the same experimental settings. 
Altogether, the above data suggest that attached $\mathrm{C}_{1} \mathrm{r}_{2} \mathrm{~S}_{2}$ proteases improve the stability of $\mathrm{C} 1 \mathrm{q}-$ $\mathrm{IgG}$ complexes on target surfaces. We propose that $\mathrm{C}_{1} \mathrm{r}_{2} \mathrm{~S}_{2}$ proteases affect the conformation of $\mathrm{C} 1 \mathrm{q}$ in a way that facilitates stable docking to surface-bound IgGs. Earlier studies reported that the solution structure of $\mathrm{C} 1 \mathrm{q}$ shows a high degree of flexibility ${ }^{62-64}$. While the six collagen arms firmly bundle via disulphide bonds in the upper stalk, such interactions are lacking below the stalk and enable a rather flexible arrangement of the gClq domains (Fig. 3C). A recent in

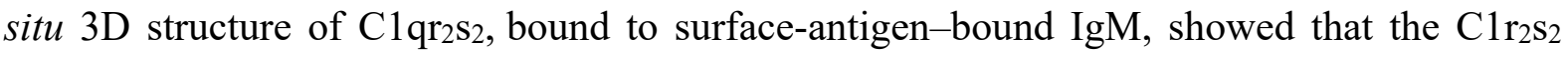
proteases are packed inside the $\mathrm{C} 1 \mathrm{q}$ molecule as two antiparallel $\mathrm{C} 1 \mathrm{rs}$ heterodimers ${ }^{65}$. Each $\mathrm{C} 1 \mathrm{rs}$ dimer binds three of the six $\mathrm{C} 1 \mathrm{q}$ collagen helices, which limits the flexibility of the collagen arms and results in a near-hexagonal arrangement of the six $\mathrm{gClq}$ domains. Based on recent observations that $\mathrm{IgG}$ hexamers are the ideal docking platform for $\mathrm{C} 1 \mathrm{q}{ }^{15,17}$, we propose that this hexagon-like arrangement of the six $\mathrm{gClq}$ domains induced by the attachment of $\mathrm{C}^{1} \mathrm{r}_{2} \mathrm{~s}_{2}$ to $\mathrm{C} 1 \mathrm{q}$ favors multivalent, high-avidity binding of $\mathrm{C} 1 \mathrm{q}$ with clustered $\mathrm{IgG}$ (Fig. 3C).

\section{Removal of $\mathrm{Clr}_{2} \mathrm{~s}_{2}$ proteases from surface-bound C1-IgG complexes can result in C1q dissociation}

Next, we wondered how the observed differences in stability between C1-IgG and C1q-IgG could explain why we observed a discrepancy between $\mathrm{C} 1 \mathrm{q}$ and $\mathrm{C} 3 \mathrm{~b}$ detection on IgG2-coated surfaces in serum (Fig. 1). Because C1q in human serum circulates as a complex with $\mathrm{C}_{1} \mathrm{r}_{2} \mathrm{~s}_{2}$ proteases, we assume that IgG2-coated $S$. aureus and DNP-beads $(1 \mu \mathrm{g} / \mathrm{ml} \mathrm{DNP})$ can recruit $\mathrm{C} 1$ and activate complement. However, since human serum contains an inhibitor that removes $\mathrm{C}_{1} \mathrm{r}_{2} \mathrm{~S}_{2}$ proteases from $\mathrm{C} 1 \mathrm{q}$, we hypothesized that subsequent removal of proteases results in dissociation of C1q-IgG complexes. To test this, we incubated IgG-covered beads with purified $\mathrm{C} 1$ and, after washing, incubated the $\mathrm{C} 1$-bound beads with human $\mathrm{C} 1$-esterase inhibitor $(\mathrm{C} 1$ INH) ${ }^{66}$. C1-INH is a human serpin that inactivates the proteases by forming a covalent bond with the catalytic site of both $\mathrm{C} 1 \mathrm{r}$ and $\mathrm{C} 1 \mathrm{~s}$. As expected, incubation of $\mathrm{C} 1-\mathrm{IgG}$ complexes on beads with $\mathrm{C} 1-\mathrm{INH}$ led to removal of $\mathrm{C}_{1} \mathrm{r}_{2} \mathrm{~S}_{2}$ proteases from $\mathrm{C} 1 \mathrm{q}$ on IgG1-, IgG2- and IgG3covered beads as evidenced by the detection of $\mathrm{C} 1-\mathrm{INH}-\mathrm{C} 1 \mathrm{r}$ and $\mathrm{C} 1-\mathrm{INH}-\mathrm{C} 1 \mathrm{~s}$ complexes in the sample supernatant using western blotting (SFig. 8). In line with our hypothesis, we found that the dissociation of $\mathrm{C}_{1} \mathrm{r}_{2} \mathrm{~s}_{2}$ by $\mathrm{C} 1-\mathrm{INH}$ had differential effects on the stability of the beadbound $\mathrm{C} 1 \mathrm{q}-\mathrm{IgG}$ complexes (Fig. 4A). Whereas dissociation of $\mathrm{C}_{1} \mathrm{r}_{2} \mathrm{~s}_{2}$ proteases by $\mathrm{C} 1-\mathrm{INH}$ did not affect $\mathrm{C} 1 \mathrm{q}-\mathrm{IgG} 3$ complexes, it caused a strong (80\%) reduction of $\mathrm{C} 1 \mathrm{q}$ binding to $\mathrm{IgG} 2-$ beads and a 10\% reduction on IgG1-beads (Fig. 4A). Similar results were obtained when $\mathrm{C}_{1} \mathrm{r}_{2} \mathrm{~s}_{2}$ proteases were removed from C1-IgG complexes using EDTA (Fig. 4A).

Altogether, these data demonstrate that $\mathrm{C} 1-\mathrm{INH}$ can dislodge $\mathrm{C} 1 \mathrm{q}$ from IgG-coated surfaces by removing $\mathrm{C}_{1} \mathrm{r}_{2} \mathrm{~S}_{2}$ from surface-bound $\mathrm{C} 1-\mathrm{IgG}$ complexes. While $\mathrm{C} 1-\mathrm{INH}$ binds and removes $\mathrm{C}_{1} \mathrm{r}_{2} \mathrm{~S}_{2}$ regardless of the IgG subclass, subsequent $\mathrm{C} 1 \mathrm{q}$ dissociation depends on the stability of $\mathrm{C} 1 \mathrm{q}-\mathrm{IgG}$ complexes (Fig. 4B). It seems likely that the dislodgement of C1q as result of $\mathrm{C}_{1} \mathrm{r}_{2} \mathrm{~S}_{2}$ dissociation explains why we could not detect $\mathrm{C} 1 \mathrm{q}$ on IgG2-beads in a serum environment (Fig. 1E). The observed deposition of $\mathrm{C} 3 \mathrm{~b}$ molecules on $\mathrm{IgG} 2$-beads in serum (Fig. 1D) furthermore suggests that $\mathrm{C} 1$ inhibitory mechanisms lag behind on $\mathrm{C} 1$-mediated cleavage of complement proteins. 


\section{Enhanced IgG oligomerization stabilizes C1q-IgG interactions}

Finally, we determined how C1q-IgG interactions are influenced by IgG oligomerization. Recent studies demonstrated that oligomerization of target-bound IgG into hexamers can be enhanced by specific point mutations that strengthen Fc-Fc contacts ${ }^{15,18}$. In contrast to the RGY mutation used above, these so-called HexaBody® mutations do not enhance hexamer formation in solution but specifically enhance hexamerization on target surfaces. Here, we modified anti-DNP IgGs using hexabody mutations E430G or E345K ${ }^{18}$ and verified that these mutations did not affect IgG binding to beads (SFig. 9A-B). Upon studying interactions with purified forms of $\mathrm{C} 1 / \mathrm{C} 1 \mathrm{q}$, we observed that both Fc mutations strongly improved binding of non-complexed C1q (i.e. C1q or C1-EDTA) to IgG1 and IgG2 on DNP-beads (Fig. 5A, SFig. 9C). For IgG3, hexabody mutations did not affect binding of non-complexed C1q (Fig. 5A, SFig. 9C). SPR experiments corroborated the results in the bead assay, showing that both the E430G and E345K mutation increase complex stability of IgG1 and IgG2 with C1q and have little effect on the association of $\mathrm{C} 1 \mathrm{q}$ with $\mathrm{IgG} 3$ (SFig. 10). Similar results were obtained for S. aureus, where introduction of E430G into anti-WTA IgG, strongly enhanced binding of noncomplexed C1q to IgG1 and IgG2, while not affecting IgG3 (SFig. 11A-B). Interestingly, we observed that hexabody mutations did not have a strong impact on the binding of fully assembled $\mathrm{C} 1$ to IgG1 and IgG2 on DNP-coated beads (Fig. 5B) or SPR chips (SFig. 10). On $S$. aureus we observed that the $\mathrm{E} 430 \mathrm{G}$ mutation induced a subtle improvement of $\mathrm{C} 1$ binding (SFig. 11C). These data suggest that unstable C1q-IgG interactions between non-complexed $\mathrm{Clq}$ and $\mathrm{IgG}$ can be overcome by promoting formation of high avidity multimeric IgG platforms on the surface. In situations where C1q-IgG complexes are already stable (e.g. for $\mathrm{C} 1$ binding to $\mathrm{IgG} 1, \mathrm{IgG} 2$ or $\mathrm{IgG} 3$ or $\mathrm{C} 1 \mathrm{q}$ binding to $\mathrm{IgG} 3$ ), hexabody mutations do not or only slightly improve $\mathrm{C} 1 \mathrm{q}-\mathrm{IgG}$ binding. The observation that $\mathrm{Fc}$ mutation E430G enhances $\mathrm{C} 1 \mathrm{q}$ binding to $\mathrm{IgG} 1$ and $\mathrm{IgG} 2$ in human $\Delta \operatorname{IgG} \Delta \operatorname{IgM}$ serum (both on beads (Fig. 5C) and S. aureus (SFig. 12)) suggests that hexabody mutations also improve the ability of IgGs to retain C1q on target surfaces in a serum environment.

We also examined whether enhanced hexamerization could affect complement binding and activation via $\mathrm{IgG} 4$, the $\mathrm{IgG}$ subclass that is considered incapable of reacting with $\mathrm{C} 1 \mathrm{q}^{39}$. Previous studies showed that the Ser at position 331 in the heavy chain of IgG4 is critical for determining its inability to bind $\mathrm{Clq}^{38,67}$. Structural modelling has furthermore shown that the two Fab arms of IgG4 obstruct its C1q binding site and that the short IgG4 hinge region allows only limited flexibility ${ }^{35-37}$. As the IgG4 used in our study also contains the essential Ser331 residue, we expected no binding to $\mathrm{C} 1 \mathrm{q}$ or $\mathrm{C} 1$. However, when we introduced the $\mathrm{E} 430 \mathrm{G}$ or E345K mutation in anti-DNP IgG4, we observed dose-dependent binding of fully assembled C1, but not C1q (Fig. 5A-B, SFig. 9C). Also on S. aureus (SFig. 11) and in SPR assays (SFig. 10), we observed that enhancing Fc-Fc interactions in $\mathrm{IgG} 4$ enabled binding to the fully assembled $\mathrm{C}$, and negligible binding to non-complexed C1q. On $S$. aureus in human serum, we could detect only low levels of C1q when introducing the hexabody mutation E430G in IgG4 (SFig. 12B). This observation is not unexpected considering our earlier hypothesis that $\mathrm{C}_{1} \mathrm{r}_{2} \mathrm{~S}_{2}$ removal by $\mathrm{C} 1-\mathrm{INH}$ results in dislodgement of $\mathrm{C} 1 \mathrm{q}$ when $\mathrm{C} 1 \mathrm{q}-\mathrm{IgG}$ interactions are unstable. Taken together, these data suggest that the poor interaction of surface-bound $\operatorname{IgG} 4$ 
with $\mathrm{C} 1 \mathrm{q}$ can be overcome in the presence of both hexabody mutations and $\mathrm{C}_{1} \mathrm{r}_{2} \mathrm{~s}_{2}$ proteases which confirms a role for the proteases in $\mathrm{C} 1 \mathrm{q}$ binding.

\section{Introduction of hexamer-enhancing mutation E430G in anti-WTA enhance complement- dependent phagocytosis of $S$. aureus}

Having demonstrated that enhanced IgG hexamerization improves the stability of C1q-IgG complexes on $S$. aureus, we wondered whether hexabody mutations also have an impact on the downstream complement effector mechanisms. In previous studies, we and others have shown that phagocytosis of $S$. aureus, which is eminent for human immune defense against these bacteria ${ }^{68}$, critically depends on the labelling of $S$. aureus with complement-derived opsonins 69-71. While antibacterial IgGs may trigger phagocytosis of $S$. aureus via Fc receptors, additional opsonization of the bacterial surface with $\mathrm{C} 3 \mathrm{~b}$ and $\mathrm{iC} 3 \mathrm{~b}$ enhances the efficacy of particle uptake via engagement of complement receptors. To study the effect of hexamerenhancing mutations on phagocytosis, we first determined the efficiency by which anti-WTA mutant IgGs triggered covalent deposition of opsonic C3b on S. aureus (Fig. 6A). Upon incubation of $S$. aureus with anti-WTA IgGs and $\Delta \mathrm{IgG} \Delta \operatorname{IgM}$ serum, we observed that the E430G mutation enhanced C3b deposition mediated by IgG1 and IgG2, but not IgG3 (Fig. 6A). Next, we determined whether enhanced IgG oligomerization on $S$. aureus improved the phagocytosis of bacteria by human neutrophils in serum (Fig. 6B). In full correspondence with the observed improvements at the level of C1q (SFig. 12B) and C3b (Fig. 6A), we observed that introduction of the E430G mutation in anti-WTA IgG1 and IgG2, but not IgG3, enhanced the phagocytic uptake of fluorescent $S$. aureus in human serum. Consistent with the finding that anti-WTA IgG4-E430G antibodies can induce C3b deposition, we observed that this antibody could induce phagocytosis of $S$. aureus (Fig. 6B). As expected, the E430G mutation did not affect the IgG-dependent phagocytosis via Fc receptors in the absence of complement (SFig. 13). Altogether these data demonstrate that Fc-engineering of anti-S. aureus IgGs can be a useful strategy to improve a complement response against this important pathogen and subsequent uptake by phagocytes.

\section{Discussion}

The classical pathway of complement activation is a major contributor to pathophysiological processes in our body, including infection, inflammation, autoimmunity and transplant rejection. Here we demonstrate in great detail how the initiating step of this pathway, namely the binding of the large $\mathrm{C} 1$ complex to the surface of IgG-labelled target cells, is influenced by its attached proteases $\mathrm{C}_{1} \mathrm{r}_{2} \mathrm{~S}_{2}$ and antibody oligomerization. Using well-defined monoclonal human antibodies and highly purified model systems to study $\mathrm{C} 1 \mathrm{q}-\mathrm{IgG}$ interactions on target surfaces, we here demonstrate that $\mathrm{C}_{1} \mathrm{r}_{2} \mathrm{~S}_{2}$ proteases affect the capacity of $\mathrm{C} 1 \mathrm{q}$ to form an avid complex with surface-bound IgG molecules. Although biophysical studies demonstrated that $\mathrm{C}_{1} \mathrm{r}_{2} \mathrm{~S}_{2}$ proteases modify the highly flexible structure of $\mathrm{C} 1 \mathrm{q}$ in solution ${ }^{62-64}$, it was not known how this would affect C1q binding to surface-bound IgG. Okada et al. (1985) proposed a potential role for $\mathrm{C}_{1} \mathrm{r}_{2} \mathrm{~S}_{2}$ proteases in $\mathrm{Clq}$ binding to polyclonal rabbit $\mathrm{IgG}$, but the mechanism and relevance for human $\operatorname{IgG}$ remained unclear ${ }^{72}$. Since our data now show that associated $\mathrm{C}_{1} \mathrm{r}_{2} \mathrm{~S}_{2}$ are important for generating stable $\mathrm{C} 1 \mathrm{q}-\mathrm{IgG}$ complexes on surfaces, we propose that the 
associated proteases limit the conformational flexibility of the $\mathrm{C} 1 \mathrm{q}$ arms and stabilize a spatial near-hexagonal arrangement of the six gClq domains that facilitates multivalent binding of C1q to antibody clusters on the surface (Fig. 3C).

Understanding how C1q molecules form a stable interaction with surface-bound IgGs is crucial for future design of therapeutic antibodies. Antibodies against bacteria and tumor cells cannot directly neutralize an infection but require activation of the immune system. For Gram-positive bacteria, the functionality of antibodies in human immune protection critically depends on the antibody's capacity to induce phagocytic killing ${ }^{68,73}$, either directly or via complement. Here we show that Fc-engineering could be a useful strategy to combat Gram-positive bacteria, as both enhancement of $\mathrm{Clq}$ and $\mathrm{C} 1$ binding to $S$. aureus can improve the opsonisation and phagocytosis of these bacteria in human serum. Recent studies on tumor cells and Neisseria gonorrhoeae have already shown that enhanced hexamerisation of IgG by Fc-engineering can potentiate the capacity of monoclonal antibodies to induce complement-mediated lysis via MAC pores ${ }^{15,18,19,23}$. Here, we demonstrate for the first time that the same mutations can be used to improve complement-dependent phagocytosis. Furthermore, since complement activation also appears crucial to induce protective antibodies against viral infections such as HIV or SARS-CoV2 ${ }^{74,75}$, designing effective complement-triggering antibodies may also be valuable for therapeutic development of anti-viral antibodies ${ }^{24}$. In addition to its role in complement activation, increasing evidence suggests that $\mathrm{C} 1 \mathrm{q}$ also enhances the efficacy of antibodies in the absence of other complement proteins. On tumor cells, it was shown that $\mathrm{C} 1 \mathrm{q}$ can act as a structural component in potentiating the efficacy of anti-tumor antibodies by inducing outside-in signaling of death receptors on tumor cells ${ }^{76}$. Furthermore, C1q directly enhances the neutralizing activity of anti-viral antibodies in vitro and in vivo ${ }^{77}$.

Our study highlights that the IgG-Fc domain has a large impact on the antibody's capacity to form stable complexes with C1q. Detailed comparison of various monoclonal antibodies indicate that the difference in stability between C1-IgG and C1q-IgG is most apparent under conditions where IgG oligomerization is less favorable. Based on our results with hexamerenhancing mutations, we think that effective IgG oligomerization can overcome the need for proteases to establish stable $\mathrm{C} 1 \mathrm{q}-\mathrm{IgG}$ complexes, likely because six antibodies can also form a stable, high avidity complex with six $\mathrm{Clq}$ arms. Furthermore, hexamer-enhancing mutations in IgG2 and IgG1 also increased C1 binding to $S$. aureus, indicating that even when $\mathrm{C}_{1} \mathrm{r}_{2} \mathrm{~S}_{2}$ is associated, efficient IgG oligomerization further stabilizes $\mathrm{C} 1-\mathrm{IgG}$ complexes. Interestingly, the finding that hexamer-enhanced IgG4 enabled binding to fully assembled $\mathrm{C} 1$, but less strongly to non-complexed C1q, could suggest that IgG4-E430G does not efficiently form hexamers. In all, we hypothesize that differences between human IgG subclasses to bind $\mathrm{Clq}$ (in the absence of proteases) could be linked to their ability to form hexameric platforms. However, also the binding affinity of IgG subclasses for $\mathrm{gClq}$ may play a role. It remains to be determined whether our experiments on beads and Gram-positive bacteria (both rigid surfaces) can be translated to highly fluidic eukaryotic or Gram-negative membranes.

Our data also shed light on the mechanisms by which $\mathrm{C} 1$-INH inactivates $\mathrm{C} 1$, which are not yet fully defined. In 1998, Chen and Boackle already showed that purified C1-INH, besides 
removing $\mathrm{C}_{1} \mathrm{r}_{2} \mathrm{~S}_{2}$, can dislodge $\mathrm{C} 1 \mathrm{q}$ molecules from an IgG-coated surface. Although they used pooled human IgG in their C1-INH studies, they suggested that the IgG subclasses might be differentially affected by $\mathrm{C} 1-\mathrm{INH}{ }^{78,79}$. Our data now provide a better insight into the subclassspecific effects of C1-INH. They show that $\mathrm{C} 1-\mathrm{INH}$ inhibits the $\mathrm{C}_{1} \mathrm{r}_{2} \mathrm{~S}_{2}$ proteases in surfacebound $\mathrm{C} 1-\mathrm{IgG}$ independent of the IgG subclass, but that it mediates C1q dissociation only in conditions where $\mathrm{C} 1 \mathrm{q}-\mathrm{IgG}$ complexes are not stable. This suggests that protease dissociation by $\mathrm{C} 1-\mathrm{INH}$ can result in either I) complete removal of both $\mathrm{C} 1 \mathrm{q}$ and $\mathrm{C} 1 \mathrm{r}_{2} \mathrm{~S}_{2}$ from the IgG-coated surface, or II) removal of only $\mathrm{C}_{1} \mathrm{r}_{2} \mathrm{~S}_{2}$ while $\mathrm{C} 1 \mathrm{q}$ remains stably bound to the IgG platform (Fig. 4B). Although $\mathrm{C} 1-\mathrm{INH}$ can inactivate $\mathrm{C} 1 \mathrm{r}$ and $\mathrm{C} 1 \mathrm{~s}$ in solution too, it is important to note that we here only investigated the effect of $\mathrm{C} 1-\mathrm{INH}$ on $\mathrm{C} 1$ that is activated on an IgG-labelled surface.

Finally, our findings are also relevant for the correct interpretation of functional antibodies in research and diagnostics. Clq binding is often used as an important parameter to determine the presence of complement-fixing antibodies. For instance in transplantation, the serum of organ recipients is tested for the presence of donor-specific complement-binding anti-HLA antibodies (which could induce antibody-mediated rejection) by measuring binding of purified $\mathrm{C} 1 \mathrm{q}^{80-83}$. Based on our findings, direct $\mathrm{C} 1 \mathrm{q}$ binding is an unreliable measure for downstream complement activation, as complement-binding IgGs that bind fully assembled $\mathrm{C} 1$, but not non-complexed C1q, are not detected. This also holds true for analyses of antibody-dependent complement activation in a human serum environment. For several antibodies, we observed that detection of surface-bound $\mathrm{C} 1 \mathrm{q}$ is an unreliable read-out for IgG-dependent complement activation. This was most evident for wild-type IgG2 and IgG4-E430G, which could potently trigger C1-mediated complement activation (and phagocytosis), while we could hardly detect $\mathrm{C} 1 \mathrm{q}$ on the surface. Although many studies have addressed the complement-binding and activating properties of antibodies, surprisingly few have differentiated between $\mathrm{C} 1 \mathrm{q}$ and $\mathrm{C} 1$. Our systematic investigation of $\mathrm{C} 1 \mathrm{q}$ versus $\mathrm{C} 1$ binding to all $\mathrm{IgG}$ subclasses in both purified and human serum environments was key for the revelation of the importance of $\mathrm{Cl}_{2} \mathrm{r}_{2} \mathrm{~s}_{2}$ in establishing stable C1q-IgG complexes.

\section{Acknowledgements}

The authors kindly thank dr. Rob de Jong, dr. Annette Stemerding, dr. Lubka Roemenia and dr. Leendert Trouw and for scientific advice. We thank dr. Brandon Garcia for providing BBK32. This work was supported by an ERC Starting Grant (639209-ComBact, to S.H.M.R) and ERC Advanced Grant (233229-Coco, to P.G.), the Utrecht University Molecular Immunology Hub (UMI-Hub, ESTIMATE), and the Swiss National Science Foundation (31003A_176104, to DR). JP acknowledges support by the European Fund for Regional Development (EFRE, Regio 13), the Federal State of Upper Austria, and the Austrian Science Fund (FWF, P33958, P34164).

\section{Conflict of interest}

AK, JAGS, PWHIP, KPMK, FJB, JS and SHMR are co-inventor on a patent describing antibody therapies against $S$. aureus. 


\section{References}

1. Lu, L. L., Suscovich, T. J., Fortune, S. M. \& Alter, G. Beyond binding: antibody effector functions in infectious diseases. Nat. Rev. Immunol. 18, 46-61 (2018).

2. Walport, M. J. Complement. First of two parts. N. Engl. J. Med. 344, 1058-66 (2001).

3. Gros, P., Milder, F. J. \& Janssen, B. J. C. Complement driven by conformational changes. Nat. Rev. Immunol. 8, 48-58 (2008).

4. Papanastasiou, M. et al. Structural Implications for the Formation and Function of the Complement Effector Protein iC3b. J. Immunol. 198, 3326-3335 (2017).

5. Ricklin, D., Hajishengallis, G., Yang, K. \& Lambris, J. D. Complement: a key system for immune surveillance and homeostasis. Nat. Immunol. 11, 785-97 (2010).

6. Bohlson, S. S., Garred, P., Kemper, C. \& Tenner, A. J. Complement NomenclatureDeconvoluted. Front. Immunol. 10, 1308 (2019).

7. Mortensen, S. et al. Structural Basis for the Function of Complement Component C4 within the Classical and Lectin Pathways of Complement. J. Immunol. 194, 54885496 (2015).

8. Law, S. K. A. \& Dodds, A. W. The internal thioester and the covalent binding properties of the complement proteins C3 and C4. Protein Sci. 6, 263-274 (2008).

9. Heesterbeek, D. A. et al. Bacterial killing by complement requires membrane attack complex formation via surface-bound C5 convertases. EMBO J. 38, e99852 (2019).

10. Morgan, B. P., Boyd, C. \& Bubeck, D. Molecular cell biology of complement membrane attack. Semin. Cell Dev. Biol. (2017) doi:10.1016/j.semcdb.2017.06.009.

11. Tomlinson, S. Complement defense mechanisms. Curr. Opin. Immunol. 5, 83-89 (1993).

12. Berends, E. T. M. et al. Distinct localization of the complement C5b-9 complex on Gram-positive bacteria. Cell. Microbiol. 15, 1955-1968 (2013).

13. Dunkelberger, J. R. \& Song, W.-C. Complement and its role in innate and adaptive immune responses. Cell Res. 20, 34-50 (2010).

14. Stuart, L. M. \& Ezekowitz, R. A. B. Phagocytosis. Immunity 22, 539-550 (2005).

15. Diebolder, C. A. et al. Complement is activated by IgG hexamers assembled at the cell surface. Science 343, 1260-3 (2014).

16. Ugurlar, D. et al. Structures of C1-IgG1 provide insights into how danger pattern recognition activates complement. Science (80-. ). 359, 794-797 (2018).

17. Strasser, J. et al. Unraveling the Macromolecular Pathways of IgG Oligomerization and Complement Activation on Antigenic Surfaces. Nano Lett. 19, 4787-4796 (2019).

18. de Jong, R. N. et al. A Novel Platform for the Potentiation of Therapeutic Antibodies Based on Antigen-Dependent Formation of IgG Hexamers at the Cell Surface. PLOS Biol. 14, (2016).

19. Wang, G. et al. Molecular Basis of Assembly and Activation of Complement Component $\mathrm{C} 1$ in Complex with Immunoglobulin G1 and Antigen. Mol. Cell 63, 135145 (2016).

20. Hughes-Jones, N. C. \& Gardner, B. Reaction between the isolated globular sub-units of the complement component C1q and IgG-complexes. Mol. Immunol. 16, 697-701 (1979).

21. Feinstein, A., Richardson, N. \& Taussig, M. I. Immunoglobulin flexibility in complement activation. Immunol. Today 7, 169-174 (1986).

22. Strasser, J. et al. Weak Fragment Crystallizable (Fc) Domain Interactions Drive the Dynamic Assembly of IgG Oligomers upon Antigen Recognition. ACS Nano 14, 2739-2750 (2020).

23. Gulati, S. et al. Complement alone drives efficacy of a chimeric antigonococcal 
monoclonal antibody. PLoS Biol. 17, e3000323 (2019).

24. Kurtovic, L. \& Beeson, J. G. Complement Factors in COVID-19 Therapeutics and Vaccines. Trends Immunol. 42, 94-103 (2021).

25. Irani, V. et al. Molecular properties of human IgG subclasses and their implications for designing therapeutic monoclonal antibodies against infectious diseases. Mol.

Immunol. 67, 171-182 (2015).

26. Laxminarayan, R. et al. Antibiotic resistance-the need for global solutions. The Lancet Infectious Diseases (2013) doi:10.1016/S1473-3099(13)70318-9.

27. Sause, W. E., Buckley, P. T., Strohl, W. R., Lynch, A. S. \& Torres, V. J. AntibodyBased Biologics and Their Promise to Combat Staphylococcus aureus Infections.

Trends in Pharmacological Sciences (2016) doi:10.1016/j.tips.2015.11.008.

28. Rogers, L. M., Veeramani, S. \& Weiner, G. J. Complement in monoclonal antibody therapy of cancer. Immunol. Res. 59, 203-210 (2014).

29. Brown, S., Santa Maria, J. P. \& Walker, S. Wall Teichoic Acids of Gram-Positive Bacteria. Annu. Rev. Microbiol. 67, 313-336 (2013).

30. van Dalen, R., Peschel, A. \& van Sorge, N. M. Wall Teichoic Acid in Staphylococcus aureus Host Interaction. Trends Microbiol. 28, 985-998 (2020).

31. Fong, R. et al. Structural investigation of human S. aureus- targeting antibodies that bind wall teichoic acid. MAbs 10,1-13 (2018).

32. Vidarsson, G., Dekkers, G. \& Rispens, T. IgG Subclasses and Allotypes: From Structure to Effector Functions. Front. Immunol. 5, 520 (2014).

33. Zwarthoff, S. A., Magnoni, S., Aerts, P. C., van Kessel, K. P. M. \& Rooijakkers, S. H. M. Depletion of IgG and IgM from human serum as naive complement source. Methods Mol. Biol. In press.

34. Cruz, A. R. et al. Staphylococcal protein A inhibits complement activation by interfering with IgG hexamer formation. Proc. Natl. Acad. Sci. In press.

35. Lu, Y. et al. Solution Conformation of Wild-Type and Mutant IgG3 and IgG4 Immunoglobulins Using Crystallohydrodynamics: Possible Implications for Complement Activation. Biophys. J. 93, 3733-3744 (2007).

36. Abe, Y., Gor, J., Bracewell, D. G., Perkins, S. J. \& Dalby, P. A. Masking of the Fc region in human IgG4 by constrained X-ray scattering modelling: implications for antibody function and therapy. Biochem. J. 432, 101-114 (2010).

37. Rayner, L. E. et al. The Fab Conformations in the Solution Structure of Human Immunoglobulin G4 (IgG4) Restrict Access to Its Fc Region. J. Biol. Chem. 289, 20740-20756 (2014).

38. Tao, M. H., Smith, R. I. \& Morrison, S. L. Structural features of human immunoglobulin $\mathrm{G}$ that determine isotype-specific differences in complement activation. J. Exp. Med. 178, 661-7 (1993).

39. Bruggemann, M. Comparison of the effector functions of human immunoglobulins using a matched set of chimeric antibodies. J. Exp. Med. 166, 1351-1361 (1987).

40. Lilienthal, G. M. et al. Potential of murine IgG1 and Human IgG4 to inhibit the classical complement and $\mathrm{Fc} \gamma$ receptor activation pathways. Front. Immunol. 9, (2018).

41. Kretschmer, A., Schwanbeck, R., Valerius, T. \& Rösner, T. Antibody Isotypes for Tumor Immunotherapy. Transfus. Med. Hemotherapy 44, 320-326 (2017).

42. Jung, D.-J. et al. Specific Serum Ig Recognizing Staphylococcal Wall Teichoic Acid Induces Complement-Mediated Opsonophagocytosis against Staphylococcus aureus. $J$. Immunol. 189, 4951-4959 (2012).

43. Barrett, D. J. \& Ayoub, E. M. IgG2 subclass restriction of antibody to pneumococcal polysaccharides. Clin. Exp. Immunol. 63, 127-34 (1986). 
44. Ferrante, A., Beard, L. J. \& Feldman, R. G. IgG subclass distribution of antibodies to bacterial and viral antigens. Pediatr. Infect. Dis. J. 9, S16-24 (1990).

45. Siber, G. R., Schur, P. H., Aisenberg, A. C., Weitzman, S. A. \& Schiffman, G. Correlation between Serum IgG-2 Concentrations and the Antibody Response to Bacterial Polysaccharide Antigens. N. Engl. J. Med. 303, 178-182 (1980).

46. Reckel, R. P., Harris, J. L., Wellerson Jr., R., Shaw, S. M. \& Kaplan, P. M. Method for detecting immune complexes in serum. (1986).

47. Garcia, B. L., Zwarthoff, S. A., Rooijakkers, S. H. M. \& Geisbrecht, B. V. Novel Evasion Mechanisms of the Classical Complement Pathway. J. Immunol. 197, 20512060 (2016).

48. Garcia, B. L., Zhi, H., Wager, B., Höök, M. \& Skare, J. T. Borrelia burgdorferi BBK32 Inhibits the Classical Pathway by Blocking Activation of the C1 Complement Complex. PLOS Pathog. 12, e1005404 (2016).

49. Xie, J. et al. Structural determination of the complement inhibitory domain of Borrelia burgdorferi BBK32 provides insight into classical pathway complement evasion by Lyme disease spirochetes. PLOS Pathog. 15, e1007659 (2019).

50. Amulic, B., Cazalet, C., Hayes, G. L., Metzler, K. D. \& Zychlinsky, A. Neutrophil function: from mechanisms to disease. Annu. Rev. Immunol. 30, 459-489 (2012).

51. Zwarthoff, S. A. et al. Functional Characterization of Alternative and Classical Pathway C3/C5 Convertase Activity and Inhibition Using Purified Models. Front. Immunol. 9, 1-13 (2018).

52. Gonzalez, M. Structural analysis of IgG2A monoclonal antibodies in relation to complement deposition and renal immune complex deposition. Mol. Immunol. 40, 307-317 (2003).

53. Watanabe, S. et al. Serum C1q as a novel biomarker of sarcopenia in older adults. FASEB J. 29, 1003-1010 (2015).

54. Naito, A. T. et al. Complement $\mathrm{Clq}$ activates canonical Wnt signaling and promotes aging-related phenotypes. Cell 149, 1298-1313 (2012).

55. Colomb, M. G., Arlaud, G. J., Villiers, C. L. \& Fothergill, L. A. Activation of C1 [and Discussion]. Philos. Trans. R. Soc. B Biol. Sci. 306, 283-292 (1984).

56. Bally, I. et al. Identification of the C1q-binding sites of human $\mathrm{C} 1 \mathrm{r}$ and $\mathrm{C} 1 \mathrm{~s}$. A refined three-dimensional model of the $\mathrm{C} 1$ complex of complement. J. Biol. Chem. 284, 19340-19348 (2009).

57. Cooper, L. J. et al. Role of heavy chain constant domains in antibody-antigen interaction. Apparent specificity differences among streptococcal IgG antibodies expressing identical variable domains. J. Immunol. 150, 2231-42 (1993).

58. Giuntini, S., Reason, D. C. \& Granoff, D. M. Combined Roles of Human IgG Subclass, Alternative Complement Pathway Activation, and Epitope Density in the Bactericidal Activity of Antibodies to Meningococcal Factor H Binding Protein. Infect. Immun. 80, 187-194 (2012).

59. Wright, J. K., Tschopp, J. \& Jaton, J. C. Preparation and characterization of chemically defined oligomers of rabbit immunoglobulin $\mathrm{G}$ molecules for the complement binding studies. Biochem. J. 187, 767-74 (1980).

60. Cooper, L. J. N., Robertson, D., Granzow, R. \& Greenspan, N. S. Variable domainidentical antibodies exhibit IgG subclass-related differences in affinity and kinetic constants as determined by surface plasmon resonance. Mol. Immunol. 31, 577-584 (1994).

61. Diebolder, C. A. et al. Complement is activated by IgG hexamers assembled at the cell surface. Science (80-. ). (2014) doi:10.1126/science.1248943.

62. Shelton, E., Yonemasu, K. \& Stroud, R. M. Ultrastructure of the Human Complement 
Component, Clq. Proc. Natl. Acad. Sci. 69, 65-68 (1972).

63. Walker, K. T. et al. Non-linearity of the collagen triple helix in solution and implications for collagen function. Biochem. J. 474, 2203-2217 (2017).

64. Poon, P. H., Schumaker, V. N., Phillips, M. L., Strang, C. J. \& Huxley, H. E. Conformation and restricted segmental flexibility of $\mathrm{C} 1$, the first component of human complement. J. Mol. Biol. 168, 563-577 (1983).

65. Sharp, T. H. et al. Insights into IgM-mediated complement activation based on in situ structures of IgM-C1-C4b. Proc. Natl. Acad. Sci. 136, 201901841 (2019).

66. Windfuhr, J. P., Alsenz, J. \& Loos, M. The critical concentration of C1-esterase inhibitor $(\mathrm{C} 1-\mathrm{INH})$ in human serum preventing auto-activation of the first component of complement (C1). Mol. Immunol. 42, 657-63 (2005).

67. Brekke, O. H., Michaelsen, T. E. \& Sandlie, I. The structural requirements for complement activation by IgG: does it hinge on the hinge? Immunol. Today 16, 85-90 (1995).

68. van Kessel, K. P. M., Bestebroer, J. \& van Strijp, J. A. G. Neutrophil-Mediated Phagocytosis of Staphylococcus aureus. Front. Immunol. 5, 467 (2014).

69. Ko, Y. P. et al. Phagocytosis Escape by a Staphylococcus aureus Protein That Connects Complement and Coagulation Proteins at the Bacterial Surface. PLoS Pathog. (2013) doi:10.1371/journal.ppat.1003816.

70. Rooijakkers, S. H. M. et al. Immune evasion by a staphylococcal complement inhibitor that acts on C3 convertases. Nat. Immunol. (2005) doi:10.1038/ni1235.

71. Rooijakkers, S. H. M., Van Wamel, W. J. B., Ruyken, M., Van Kessel, K. P. M. \& Van Strijp, J. A. G. Anti-opsonic properties of staphylokinase. Microbes Infect. 7, 476-484 (2005).

72. Okada, M., Udaka, K. \& Utsumi, S. Co-operative interaction of subcomponents of the first component of complement with IgG: a functional defect of dimeric Facb from rabbit IgG. Mol. Immunol. 22, 1399-406 (1985).

73. Weber, S. S. \& Oxenius, A. Antibody-Dependent Cellular Phagocytosis and Its Impact on Pathogen Control. in Antibody Fc 29-47 (Elsevier, 2014). doi:10.1016/B978-0-12394802-1.00002-9.

74. Richardson, S. I. et al. HIV-specific Fc effector function early in infection predicts the development of broadly neutralizing antibodies. PLoS Pathog. 14, e1006987 (2018).

75. Atyeo, C. et al. Distinct Early Serological Signatures Track with SARS-CoV-2 Survival. Immunity 53, 524-532.e4 (2020).

76. Overdijk, M. B. et al. Dual Epitope Targeting and Enhanced Hexamerization by DR5 Antibodies as a Novel Approach to Induce Potent Antitumor Activity Through DR5 Agonism. Mol. Cancer Ther. 19, 2126-2138 (2020).

77. Mehlhop, E. et al. Complement protein $\mathrm{C} 1 \mathrm{q}$ reduces the stoichiometric threshold for antibody-mediated neutralization of West Nile virus. Cell Host Microbe 6, 381-391 (2009).

78. Chen, C. H., Lam, C. F. \& Boackle, R. J. C1 inhibitor removes the entire C1qr2s2 complex from anti-C1Q monoclonal antibodies with low binding affinities. Immunology 95, 648-54 (1998).

79. Chen, C.-H. \& Boackle, R. J. A Newly Discovered Function for C1 Inhibitor, Removal of the Entire C1qr2s2Complex from Immobilized Human IgG Subclasses. Clin. Immunol. Immunopathol. 87, 68-74 (1998).

80. Chen, G., Sequeira, F. \& Tyan, D. B. Novel C1q assay reveals a clinically relevant subset of human leukocyte antigen antibodies independent of immunoglobulin $\mathrm{G}$ strength on single antigen beads. Hum. Immunol. 72, 849-858 (2011).

81. Thurman, J. M., Panzer, S. E. \& Le Quintrec, M. The role of complement in antibody 
mediated transplant rejection. Mol. Immunol. 112, 240-246 (2019).

82. Valenzuela, N. M. \& Schaub, S. The Biology of IgG Subclasses and Their Clinical Relevance to Transplantation. 102, (2018).

83. Taylor, C. J. et al. Technical Limitations of the C1q Single-Antigen Bead Assay to Detect Complement Binding HLA-Specific Antibodies. Transplantation 101, 12061214 (2017).

84. White, K. D., Frank, M. B., Foundling, S. \& Waxman, F. J. Effect of immunoglobulin variable region structure on $\mathrm{C} 3 \mathrm{~b}$ and $\mathrm{C} 4 \mathrm{~b}$ deposition. Mol. Immunol. 33, 759-768 (1996).

85. Cruz, A. R. et al. Staphylococcal protein A inhibits complement activation by interfering with IgG hexamer formation. bioRxiv 2020.07.20.212118 (2020) doi:10.1101/2020.07.20.212118.

86. Lehar, S. M. et al. Novel antibody-antibiotic conjugate eliminates intracellular S. aureus. Nature 527, 323-328 (2015).

87. Gonzales, N. Minimizing immunogenicity of the SDR-grafted humanized antibody CC49 by genetic manipulation of the framework residues. Mol. Immunol. 40, 337-349 (2003).

88. Kabat, E. A., (U.S.), N. I. of H. \& University., C. Sequences of proteins of immunological interest. (U.S. Dept. of Health and Human Services, Public Health Service, National Institutes of Health, 1991).

89. Sibbald, M. J. J. B. et al. Synthetic Effects of secG and secY2 Mutations on Exoproteome Biogenesis in Staphylococcus aureus. J. Bacteriol. 192, 3788-3800 (2010).

90. Kuipers, A. et al. The Staphylococcus aureus polysaccharide capsule and Efbdependent fibrinogen shield act in concert to protect against phagocytosis. Microbiology 162, 1185-1194 (2016).

91. Bestebroer, J. et al. Staphylococcal superantigen-like 5 binds PSGL-1 and inhibits Pselectin-mediated neutrophil rolling. Blood 109, 2936-2943 (2007).

92. Ando, T. et al. A high-speed atomic force microscope for studying biological macromolecules. Proc. Natl. Acad. Sci. 98, 12468-12472 (2001).

93. Preiner, J. et al. IgGs are made for walking on bacterial and viral surfaces. Nat. Commun. 5, 1-8 (2014).

94. Burton, D. R. et al. Efficient neutralization of primary isolates of HIV-1 by a recombinant human monoclonal antibody. Science 266, 1024-1027 (1994). 


\section{Figure Legends}

\section{Figure 1. IgG-mediated complement activation does not always correlate with detection of C1q}

(A-B) C3b deposition (A) and C1q binding (B) on anti-WTA IgG-labelled S. aureus Wood46 bacteria upon incubation with $5 \%$ or respectively $1 \% \Delta \operatorname{IgG} \Delta \operatorname{IgM}$ serum as determined by flow cytometry. Data represent mean fluorescence intensity (FI) \pm SD (left graph) or mean area under the curve (AUC) $\pm \mathrm{SD}$ (right graph) of three independent experiments. AUC of C3b and C1q binding curves was determined after subtraction of a 2500 (C3b) or 200 (C1q) baseline, respectively. (C) Phagocytosis of fluorescently labelled $S$. aureus Wood46 in either RPMI buffer or $1 \% \Delta \operatorname{IgG} \Delta \operatorname{IgM}$ serum supplemented with anti-WTA IgG2 and human neutrophils. Bacterial uptake was quantified by flow cytometry and displayed as the percentage of GFPpositive neutrophils. Data represent mean \pm SD of three independent experiments. (D-E) C3b deposition (D) and detection of C1q (E) on beads coated with $1 \mu \mathrm{g} / \mathrm{ml}$ DNP upon incubation with $\Delta \operatorname{IgG} \Delta \operatorname{IgM}$ serum and human monoclonal anti-DNP IgG $(20 \mathrm{nM})$. Deposition of C3b and $\mathrm{C} 1 \mathrm{q}$ molecules on the beads was determined by flow cytometry. Data represent geometric mean \pm SD of three independent experiments.

\section{Figure 2. $\mathrm{C1}_{2} \mathrm{~s}_{2}$ proteases enhance the binding of C1q to target-bound IgG}

(A) Schematic presentation of $\mathrm{C} 1$ consisting of the recognition molecule $\mathrm{Clq}$ in complex with a tetramer of proteases $\mathrm{C} 1 \mathrm{r}$ and $\mathrm{C} 1 \mathrm{~s}\left(\mathrm{Clr}_{2} \mathrm{~s}_{2}\right)$. $\mathrm{C} 1 \mathrm{q}$ consists of six polypeptide chains that come together in an $\mathrm{N}$-terminal stalk. At their $\mathrm{C}$-terminus, all six chains end in a globular domain (gC1q) that recognizes $\mathrm{Fc}$ domains of IgM and clustered IgGs. The $\mathrm{C}_{1} \mathrm{r}_{2} \mathrm{~S}_{2}$ tetramer associates to the collagen arms of $\mathrm{Clq}$ via $\mathrm{Ca}^{2+}$-dependent interactions ${ }^{56}$. The proteases dissociate from $\mathrm{C} 1 \mathrm{q}$ in the presence of EDTA, a calcium-chelator. (B) Binding of different forms of purified $\mathrm{C} 1$ to DNP-beads ( $1 \mu \mathrm{g} / \mathrm{ml} \mathrm{DNP}$ ) coated with $20 \mathrm{nM}$ anti-DNP IgG1-4. ' $\mathrm{C} 1$ ' indicates the fully

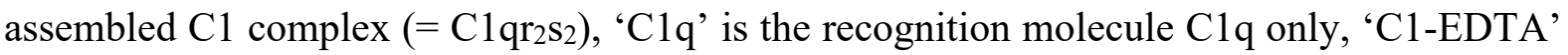
sample consists of $\mathrm{C} 1 \mathrm{q}, \mathrm{C} 1 \mathrm{r}$ and $\mathrm{C} 1 \mathrm{~s}$, but the proteases are not attached to $\mathrm{C} 1 \mathrm{q}$ (because 10 mM EDTA disrupts the $\mathrm{Ca}^{2+}$-dependent association between proteases and $\left.\mathrm{C} 1 \mathrm{q}\right)$. (C) Binding of different forms of purified C1 to IgG3-labelled beads coated with $0.003 \mu \mathrm{g} / \mathrm{ml}(\sim 300$-fold lower than in (B)). The dotted lines show aspecific binding of the $\mathrm{C} 1 \mathrm{q}$ molecules in absence of IgG3. (B-C) Bound C1q was detected by polyclonal anti-C1q antibodies and flow cytometry. Data represent mean $\pm \mathrm{SD}$ of three independent experiments.

\section{Figure 3: $\mathrm{C}_{1} \mathbf{r}_{2} \mathrm{~s}_{2}$ proteases enhance the stability of surface-bound $\mathrm{C} 1 \mathrm{q}-\mathrm{IgG}$ complexes}

(A) SPR experiment showing binding of purified $\mathrm{C} 1$ or $\mathrm{Clq}$ to sensor chips with immobilized DNP coated with $20 \mathrm{nM}$ anti-DNP IgG. C1 or C1q was injected for 60 seconds to allow association, after which the injection was stopped and dissociation was monitored. Representative of two independent experiments. SPR responses were normalized to account for the molecular weight difference between $\mathrm{C} 1(766 \mathrm{kDa})$ and $\mathrm{C1q}(410 \mathrm{kDa})$. RU, response units. (B) HS-AFM image sequence of anti-DNP IgG1-RGY in complex with $\mathrm{Clq}$ in the presence of C1q in solution (upper panel; taken from Movie S1) and C1 in the absence of C1 in solution (lower panel; taken from Movie S2). The depicted height scale is relative to the membrane surface. The heights of the respective complexes were $12.2 \pm 0.6 \mathrm{~nm}$ (anti-DNP 
IgG1-RGY) ${ }^{17}, 20.2 \pm 1.5 \mathrm{~nm}$ (anti-DNP IgG1-RGY + C1q), and $18.5 \pm 1.7 \mathrm{~nm}$ (anti-DNP IgG1-RGY + C1). (C) gC1q domains mediate binding to IgG. In C1q, the $\mathrm{gClq}$ domains are flexible. We hypothesize that in $\mathrm{C} 1$ the associated $\mathrm{C}_{1} \mathrm{r}_{2} \mathrm{~S}_{2}$ proteases fix the collagen arms and thereby orient the $\mathrm{gClq}$ domains in a hexagon-like platform that favors binding to (hexameric) IgG clusters.

Figure 4: Removal of $\mathrm{C}_{1} \mathrm{r}_{2} \mathrm{~s}_{2}$ proteases from surface-bound $\mathrm{C} 1-\mathrm{IgG}$ complexes can result in C1q dissociation

(A) Detection of C1q on IgG-coated DNP-beads that were first labelled with purified $\mathrm{C} 1$ and subsequently incubated with $10 \mathrm{mM}$ EDTA or $200 \mathrm{nM} \mathrm{C1-INH}$ to remove C1r and C1s proteases. Data represent geometric mean $\pm \mathrm{SD}$ of three independent experiments. Unpaired $\mathrm{t}$ test (buffer vs. EDTA; buffer vs. C1-INH); ${ }^{*} P<0.05$, all other conditions not significant. (B) Schematic cartoon of our hypothesis that $\mathrm{C}_{1} \mathrm{r}_{2} \mathrm{~s}_{2}$ dissociation by $\mathrm{C} 1-\mathrm{INH}$ can result in $\mathrm{C} 1 \mathrm{q}$ dislodgement depending on the stability of the C1q-IgG complex. Our data suggest that removal of the $\mathrm{C} 1 \mathrm{r}$ and $\mathrm{C} 1$ s proteases from surface-bound $\mathrm{C} 1$ by $\mathrm{C} 1-\mathrm{INH}$ can result in two situations: (I) C1q dissociates from the surface-bound IgGs in the case the remaining $\mathrm{C} 1 \mathrm{q}-\mathrm{IgG}$ complexes are unstable, e.g. for $\mathrm{C} 1 \mathrm{q}-\mathrm{IgG} 2$ complexes; or (II) $\mathrm{C} 1 \mathrm{q}$ remains bound since it has formed a stable interaction with the surface-bound IgGs.

\section{Figure 5: Enhanced IgG oligomerization stabilizes C1q-IgG interactions}

(A-B) Binding of purified C1q (A) or C1 (B) to DNP-beads (1 $\mu \mathrm{g} / \mathrm{ml} \mathrm{DNP)} \mathrm{labelled} \mathrm{with} 20$ $\mathrm{nM}$ anti-DNP IgG, either wild-type or containing hexamer-enhancing mutations E430G or E345K. (C) Detection of C1q on DNP-beads (1 $\mu \mathrm{g} / \mathrm{ml} \mathrm{DNP})$ after incubation with $1 \%$ $\Delta \mathrm{IgG} \Delta \mathrm{IgM}$ serum supplemented with wild-type or mutated (E430G) anti-DNP IgG. (A-C) C1q was detected by flow cytometry. Data represent geometric mean \pm SD of three independent experiments.

Figure 6: Introduction of hexamer-enhancing mutation E430G in anti-WTA can enhance complement-dependent phagocytosis of $S$. aureus

(A) C3b deposition on $S$. aureus Wood46 after incubation of bacteria in $5 \% \Delta \operatorname{IgG} \Delta \operatorname{IgM}$ serum supplemented with anti-WTA IgG (wild-type or E430G mutant). Data represent mean \pm SD of three independent experiments. (B) Phagocytosis in the absence and presence of complement. Phagocytosis of fluorescently labelled $S$. aureus Wood46 in either RPMI buffer or 1\% $\Delta \operatorname{IgG} \Delta \operatorname{IgM}$ serum supplemented with anti-WTA IgG (wild-type or E430G mutant) and human neutrophils. Bacterial uptake was quantified by flow cytometry and displayed as the number of GFP-positive neutrophils relative to IgG1 wild-type. Data represent relative mean $\pm \mathrm{SD}$ of three independent experiments. Phagocytosis data shown for wild-type IgG2 (buffer and serum condition) are identical to the data shown in Fig. 1C. 


\section{Supplemental Figure 1: Schematic overview of the classical complement pathway}

(A) $\mathrm{C} 1$ binds surface-bound antibodies (either $\operatorname{IgG}$ or $\operatorname{IgM}$ ) and, by cleaving $\mathrm{C} 4$ and $\mathrm{C} 2$, generates a surface-bound $\mathrm{C} 3$ convertase enzyme $(\mathrm{C} 4 \mathrm{~b} 2 \mathrm{~b})$ that catalyzes the rapid deposition of $\mathrm{C} 3 \mathrm{~b}$ molecules onto the target surface. $\mathrm{C} 3 \mathrm{~b}$ evokes phagocytosis of the target cell, formation of $\mathrm{C} 5$ convertases and formation of the membrane attack complex (MAC). C1 binds to antibodies on the surface via the globular heads of subunit $\mathrm{C} 1 \mathrm{q}$. C1q binding requires oligomerization of surface-bound IgGs into ordered hexamers that are held together by noncovalent Fc-Fc contacts. (B) The $\mathrm{C} 1$ complex $\left(\mathrm{C} \mathrm{qr}_{2} \mathrm{~s}_{2}\right)$ consists of one recognition molecule $\mathrm{C} 1 \mathrm{q}$ (green) and an associated protease heterotetramer consisting of $\mathrm{C} 1 \mathrm{r}$ (pink) and $\mathrm{C} 1 \mathrm{~s}$ (purple) $\left(\mathrm{C} \mathrm{r}_{2} \mathrm{~s}_{2}\right)$. $\mathrm{C} 1 \mathrm{q}$ consists of six collagen arms that each end in a globular domain $(\mathrm{gC} 1 \mathrm{q})$ at their C-terminus. Each $\mathrm{gClq}$ domain can bind to the $\mathrm{Fc}$ tail of an IgG antibody.

\section{Supplemental Figure 2: IgG binding to $S$. aureus in serum}

Binding of anti-WTA $\operatorname{IgG}$ (wild-type) to $S$. aureus Wood46 in $1 \% \Delta \operatorname{IgG} \Delta \operatorname{IgM}$ serum. Data represent mean $\pm \mathrm{SD}$ of three independent experiments.

\section{Supplemental Figure 3: C3b deposition on $S$. aureus in serum is C1-dependent.}

$\mathrm{C} 3 \mathrm{~b}$ deposition on $S$. aureus Newman $\triangle$ spa/sbi bacteria, labelled with either anti-WTA IgG1, $\mathrm{IgG} 2$ or IgG3 in $1 \% \Delta \mathrm{IgG} \Delta \mathrm{IgM}$ serum in absence ('control') or presence of monoclonal anti$\mathrm{C} 1 \mathrm{q}$ antibody (blocking the $\mathrm{gC} 1 \mathrm{q}$ ) or BBK32 (blocking C1r-dependent cleavage of C4). Data represent mean $\pm \mathrm{SD}$ of three independent experiments.

\section{Supplemental Figure 4: Verification of DNP-beads as model surface for antibody- dependent complement activation}

(A) Schematic presentation of the DNP-bead model. Streptavidin-beads (with a diameter comparable to bacterial cells, $2.7 \mu \mathrm{m}$ ) are labelled with DNP-biotin, which is recognized by monoclonal anti-DNP IgGs. SA = streptavidin. (B) Streptavidin-beads were labelled with different concentrations of DNP-biotin and incubated with anti-DNP IgG1 and goat anti-human kappa-AlexaFluor647 in flow cytometry. Data represent mean $\pm \mathrm{SD}$ of two independent experiments. (C) Binding of anti-DNP IgG subclasses to DNP-beads ( $1 \mu \mathrm{g} / \mathrm{ml} \mathrm{DNP}$ ) as determined by flow cytometry. Data represent mean $\pm \mathrm{SD}$ of three independent experiments. (D) Binding of different forms of purified C1 to DNP-beads ( $1 \mu \mathrm{g} / \mathrm{ml} \mathrm{DNP})$ that were not labelled with IgG. C1q was detected by polyclonal anti-C1q antibodies and flow cytometry. Data represent mean \pm SD of three independent experiments. (E) Binding of different forms of $\mathrm{C} 1$ to DNP-beads ( $1 \mu \mathrm{g} / \mathrm{ml} \mathrm{DNP}$ ) labelled with $20 \mathrm{nM} \mathrm{IgG}$ as detected by western blotting. After incubation with $\mathrm{C} 1 / \mathrm{C} 1 \mathrm{q} / \mathrm{C} 1$-EDTA, beads were pelleted and supernatant was discarded. The bead pellet was boiled in SDS sample buffer for 5 minutes and then again pelleted. The supernatant, containing the previously surface-bound proteins, was next analysed by SDSPAGE and western blotting with anti-Clq antibodies. The first two lanes show controls consisting of $3 \mathrm{nM}$ purified $\mathrm{Clq}$ or $\mathrm{C} 1$. Representative blot of three experiments.

\section{Supplemental Figure 5: C1q binding to IgG-labelled $S$. aureus bacteria is similar to that in the DNP-bead model}


(A) Binding of anti-WTA IgG (wild-type) to $S$. aureus Wood46 in RPMI buffer. (B) Binding of different forms of purified $\mathrm{C} 1$ to $S$. aureus Wood46 bacteria that were not labelled with IgG.

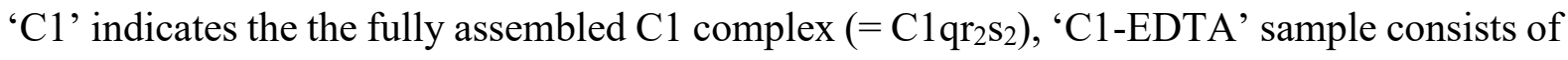
$\mathrm{C} 1 \mathrm{q}, \mathrm{C} 1 \mathrm{r}$ and $\mathrm{C} 1 \mathrm{~s}$, but the proteases are not attached to $\mathrm{C} 1 \mathrm{q}$ (because $10 \mathrm{mM}$ EDTA disrupts the $\mathrm{Ca}^{2+}$-dependent association between proteases and $\mathrm{C} 1 \mathrm{q}$ ). $\mathrm{C} 1 \mathrm{q}$ was detected by polyclonal anti-C1q antibodies and flow cytometry. (C) Binding of purified $\mathrm{C} 1$ on S. aureus Wood46 bacteria labelled with $50 \mathrm{nM}$ anti-WTA IgG, in the absence or presence of EDTA. C1q binding was detected by polyclonal anti-C1q antibodies and flow cytometry. (A-C) Data represent mean $\pm \mathrm{SD}$ of three independent experiments.

\section{Supplemental Figure 6: IgG3 potently mediates C3b deposition on beads coated with lower DNP concentrations}

$\mathrm{C} 3 \mathrm{~b}$ deposition in serum on beads loaded with a lower DNP concentration. Streptavidin-beads were loaded with $0.003 \mu \mathrm{g} / \mathrm{ml}$ biotinylated DNP antigen ( $\sim 300$-fold lower than in previous experiments) and subsequently incubated with human monoclonal anti-DNP $\operatorname{IgG}(20 \mathrm{nM})$ and human $\triangle \mathrm{IgG} \Delta \mathrm{IgM}$ serum. Deposition of $\mathrm{C} 3 \mathrm{~b}$ molecules on the beads was determined by flow cytometry. Data represent geometric mean $\pm \mathrm{SD}$ of two independent experiments.

\section{Supplemental Figure 7: Binding experiments by SPR}

(A) Preparation of DNP and control surfaces on SPR sensor chip. A flat carboxymethyldextran surface was activated using NHS/EDC and aminated with ethylenediamine. A DNP construct with a short PEG spacer and amine-reactive NHS group was coupled to the active surface. Methoxy-PEG(4)-NHS was used to prepare a control surface with similar characteristics but missing the DNP antigen. (B) Binding of anti-DNP IgG1-4 (20 nM) to the DNP surface. All IgG isotypes associated to the active surface, providing a stable IgG baseline for subsequent $\mathrm{C} 1$ or C1q binding. Data show reference-subtracted signals on DNP surface. (C) Example of a typical experimental SPR injection sequence on DNP-labelled and control surfaces. IgG capturing and injection of $\mathrm{C} 1$ protein only induced detectable SPR signals on the DNP surface but not on the $\mathrm{MeO}$ control surface. Injection of glycine buffer $(\mathrm{pH} 2.0)$ led to a complete regeneration of the DNP surface. The example sequence shown here: IgG3-C1. (D) Binding of purified C1q and $\mathrm{C} 1$ to an SPR sensor chip subsequently coated with immobilized DNP and 4 $\mathrm{nM}$ anti-DNP IgG3 (5-fold lower than in (B)). C1q or C1 was injected for 60 seconds to allow association, after which the injection was stopped and dissociation was monitored. $\mathrm{C} 1$ dissociated slower than $\mathrm{C} 1 \mathrm{q}$ alone, indicating that $\mathrm{C} 1$ binds more stable. (B-D) Data show one representative of two independent experiments. SPR responses were normalized to account for the molecular weight difference between $\mathrm{C} 1(766 \mathrm{kDa})$ and $\mathrm{C} 1 \mathrm{q}(410 \mathrm{kDa})$. RU, reponse units.

\section{Supplemental Figure 8: Removal of C1r and C1s by C1-INH can result in dislodgement of C1q from surface-bound IgG}

(A-D) Detection of C1r, C1s, C1-INH and C1q upon incubation of surface-bound C1 complexes with C1-INH. First, DNP-beads were labelled with anti-DNP IgG (20 nM IgG1 (AB), or IgG2, IgG3, IgG4 (C-D)) and C1 (1 nM), successively. Next, beads were incubated with C1-INH $(200 \mathrm{nM})$ or a buffer control. Beads were pelleted and the supernatant was collected and incubated 1:1 (v/v) with SDS sample buffer $(+\mathrm{DTT})$. (A, C) The presence of dissociated 
C1-INH-protease complexes in the supernatant samples was shown by western blotting with polyclonal anti-C1r, anti-C1s and anti-C1-INH. Red triangles indicate the complexes. Detection of C1-INH was only done for samples incubated with C1-INH. Controls shown (leftsided boxes) consist of purified C1 (3 nM), C1r (10 nM), C1s (10 nM) or C1-INH (10 nM). Representative blots of two experiments. Explanation of bands: Inhibition of $\mathrm{C} 1 \mathrm{r}$ or $\mathrm{C} 1 \mathrm{~s}$ (associated to surface-bound C1q) occurs through covalent binding of C1-INH (110 kDa) to the $\mathrm{C} 1 \mathrm{r} / \mathrm{C} 1 \mathrm{~s}$ serine protease (SP) domain in the $\mathrm{C} 1 \mathrm{r} / \mathrm{C} 1 \mathrm{~s}$ light chain (LC), which separates from the $\mathrm{C} 1 \mathrm{r} / \mathrm{C} 1 \mathrm{~s}$ heavy chain under reducing conditions. Formation of inhibitor-protease complexes is thus visible by detection of C1-INH-C1 $\mathrm{r}_{\mathrm{LC}}(\sim 145 \mathrm{kDa})$ or C1-INH-C1 $\mathrm{s}_{\mathrm{LC}}(\sim 138 \mathrm{kDa})$ complexes, indicated by red triangles. $(\mathbf{B}, \mathbf{D})$ The dislodgement of $\mathrm{C} 1 \mathrm{q}$ into the supernatant was determined by western blotting using polyclonal anti-C1q antibodies. Blue triangles indicate the presence of C1q chains A, B and C in the supernatant. Controls shown in the leftsided boxes consist of purified C1 (3 nM). Representative blot of two experiments.

\section{Supplemental Figure 9: IgG and C1q binding to DNP-beads coated with hexamer- enhanced IgG mutants}

(A) Binding of anti-DNP IgG (wild-type, E430G and E345K mutants; $20 \mathrm{nM}$ ) to DNP-beads $(1 \mu \mathrm{g} / \mathrm{ml} \mathrm{DNP})$ in PBS-TH (PBS with $0.05 \%$ (v/v) Tween and $0.5 \%$ human serum albumin). Unpaired $t$ test (wild-type vs E430G or wild-type vs E345K) showed no significant differences $(P>0.05)$. (B) Binding of anti-DNP IgG (wild-type and E430G; $30 \mathrm{nM}$ ) to DNP-beads (1 $\mu \mathrm{g} / \mathrm{ml} \mathrm{DNP}$ ) in $1 \% \Delta \operatorname{IgG} \Delta \operatorname{IgM}$ serum. (C) Binding of C1-EDTA to DNP-beads ( $1 \mu \mathrm{g} / \mathrm{ml} \mathrm{DNP})$ labelled with anti-DNP IgG (wild-type, E430G or E345K mutants; $20 \mathrm{nM}$ ). 'C1-EDTA' sample consists of $\mathrm{C} 1 \mathrm{q}, \mathrm{C} 1 \mathrm{r}$ and $\mathrm{C} 1 \mathrm{~s}$, but the proteases are not attached to $\mathrm{C} 1 \mathrm{q}$ (because $10 \mathrm{mM}$ EDTA disrupts the $\mathrm{Ca}^{2+}$-dependent association between proteases and $\mathrm{C} 1 \mathrm{q}$ ). $\mathrm{C} 1 \mathrm{q}$ binding was detected by polyclonal anti-C1q antibodies and flow cytometry. (A-C) Data represent geometric mean \pm SD of three independent experiments.

\section{Supplemental Figure 10: Enhanced IgG oligomerization stabilizes C1q-IgG interactions on DNP-coated surfaces in SPR experiments}

SPR experiments showing binding of purified $\mathrm{C} 1$ or $\mathrm{C} 1 \mathrm{q}$ to sensor chips that are subsequently coated with immobilized DNP and with $20 \mathrm{nM}$ anti-DNP IgG (either wild-type, E430G or $\mathrm{E} 345 \mathrm{~K}$ mutants). $\mathrm{C} 1$ or $\mathrm{C} 1 \mathrm{q}$ was injected for 60 seconds to allow association, after which the injection was stopped and dissociation was monitored. Data show representative of two independent experiments. SPR responses were normalized to account for the molecular weight difference between $\mathrm{C} 1(766 \mathrm{kDa})$ and $\mathrm{C} 1 \mathrm{q}(410 \mathrm{kDa})$. Data shown for wild-type IgG1-4 are identical to those shown in Fig. 3A. RU, reponse units.

\section{Supplemental Figure 11: Enhanced IgG oligomerization stabilizes C1q-IgG interactions on $S$. aureus bacteria}

(A) Binding of anti-WTA IgG (wild-type and E430G mutant) to S. aureus Wood46 in RPMI buffer. Data shown for wild-type IgG1-4 are identical to those shown in SFig. 5A. (B-C) Binding of different forms of purified $\mathrm{C} 1$ on $S$. aureus Wood46 bacteria labelled with $50 \mathrm{nM}$ anti-WTA IgG (either wild-type or E430G mutant). 'C1-EDTA' samples (B) consist of C1q, $\mathrm{C} 1 \mathrm{r}$ and $\mathrm{C} 1 \mathrm{~s}$, but the proteases are not attached to $\mathrm{Clq}$ (because $10 \mathrm{mM}$ EDTA disrupts the 
$\mathrm{Ca}^{2+}$-dependent association between proteases and $\mathrm{C} 1 \mathrm{q}$ ). ' $\mathrm{C} 1$ ' (C) indicates the the fully assembled $\mathrm{C} 1$ complex $\left(=\mathrm{C}_{\left.1 \mathrm{qr}_{2} \mathrm{~s}_{2}\right)}\right.$. $\mathrm{C} 1 \mathrm{q}$ binding was detected by polyclonal anti-C1q antibodies and flow cytometry. Data shown for wild-type IgG1-4 are identical to those shown in SFig. 5C. (A-C) Data represent mean $\pm \mathrm{SD}$ of three independent experiments.

\section{Supplemental Figure 12: Enhanced IgG oligomerization stabilizes C1q-IgG interactions} on $S$. aureus bacteria in serum

(A) Binding of anti-WTA IgG (wild-type and E430G mutant) to S. aureus Wood46 in 1\% $\Delta \mathrm{IgG} \Delta \mathrm{IgM}$ serum. Data represent mean $\pm \mathrm{SD}$ of three independent experiments. Data shown for wild-type IgG1-4 are identical to those shown in SFig. 2. (B) Binding of C1q to anti-WTA IgG-labelled $S$. aureus Wood46 bacteria in $1 \% \Delta \operatorname{IgG} \Delta \operatorname{IgM}$ serum as determined by flow cytometry. Data represent mean $\pm \mathrm{SD}$ of three independent experiments. Data shown for wildtype IgG1-4 are identical to those shown in Fig. 1B.

Supplemental Figure 13: Enhanced IgG oligomerization does not influence FcRdependent phagocytosis of $S$. aureus bacteria by human neutrophils

Phagocytosis in the absence of complement. Phagocytosis of fluorescently labelled S. aureus Wood46 in RPMI buffer supplemented with anti-WTA IgG (wild-type or E430G mutant) and human neutrophils. Bacterial uptake was quantified by flow cytometry and displayed as the number of GFP-positive neutrophils relative to IgG1 wild-type. Data represent relative mean $\pm \mathrm{SD}$ of three independent experiments. Phagocytosis data shown for wild-type IgG are identical to the data shown in Fig. 6B.

Movie S1: HS-AFM of the IgG1-RGY - C1q complex in the presence of C1q in solution. Initially detected $\mathrm{C} 1 \mathrm{q}$ molecules subsequently dissociate from IgG hexamers. Image size: 400 x $400 \mathrm{~nm}^{2}\left(100 \times 100 \mathrm{pixel}^{2}\right), 1 \mathrm{~s} /$ frame.

Movie S2: HS-AFM of the IgG1-RGY - C1 complex in the absence of C1 in solution. C1 molecules remain stably bound to IgG hexamers during HS-AFM imaging. Image size: $400 \mathrm{x}$ $400 \mathrm{~nm}^{2}\left(100 \times 100 \mathrm{pixel}^{2}\right), 1 \mathrm{~s} /$ frame.

\section{Supplemental Table 1: Protein sequences used for antibody production}

Variable and constant heavy and light chain protein sequences used for antbody production. The residues E345 and E430 are highlighted in grey. 


\section{Methods}

\section{Complement proteins}

All complement proteins were obtained from Complement Technology Inc. (TX, USA): C1 (A098), C1q (A099), C1r (A102), C1s (A104) and C1-inhibitor (A140).

\section{Depletion of IgG and IgM from human serum}

Human serum from 20 healthy donors was pooled and depleted of $\mathrm{IgG}$ and $\operatorname{IgM}$ as previously described ${ }^{33}$. Informed consent was obtained from all subjects in accordance with the Declaration of Helsinki. Approval from the Medical Ethics Committee of the University Medical Center Utrecht was obtained (METC protocol 07-125/C approved on March 1, 2010). Briefly, IgG and IgM were separated from serum by affinity chromatography using HiTrap Protein G High Performance column (Cytiva, GE Healthcare) and CaptureSelect IgM Affinity Matrix (Thermofisher Scientific). Complement levels and complement activity were determined after depletion, using ELISA and classical/alternative pathway hemolytic assays respectively. Since C1q was partially co-depleted during the procedure, the $\Delta \operatorname{IgG} \Delta \operatorname{IgM}$ serum was reconstituted with $\mathrm{C} 1 \mathrm{q}$ to physiological levels $(70 \mu \mathrm{g} / \mathrm{ml})$.

\section{Production of human monoclonal antibodies}

Recombinant monoclonal anti-DNP (DNP-G2a2) IgG1 antibody with the triple RGY mutation ${ }^{15}$ used for HS-AFM experiments was obtained from Genmab (Utrecht, the Netherlands) ${ }^{16,84}$. Other monoclonal human anti-DNP and anti-WTA IgG of the four IgG subclasses were produced recombinantly in human Expi293F cells (Life Technologies) as described before ${ }^{51}$ with minor changes. The constant regions of heavy (HC) and light chain (LC) were cloned separately into pcDNA3.4 (ThermoFisher Scientific). Subsequently, gBlocks containing codon optimized variable (VH and VL) region sequences with an upstream KOZAK and HAVT20 signal peptide (Integrated DNA Technologies, IA, USA) were cloned upstream the HC and LC regions, respectively, using Gibson assembly (New England Biolabs). NheI and BsiWI were used as the 3' cloning sites for $\mathrm{VH}$ and $\mathrm{VL}$, respectively, in order to preserve the immunoglobulin heavy and kappa light chain amino acid sequence.

Sequences of IgG1, IgG2, IgG3, IgG4 variable and constant heavy and light chains were previously described ${ }^{51,85}$ (Supplemental Table 1). VH and VL sequences were derived from previously described anti-WTA GlcNAc- $\beta-4497$ (anti-WTA-4497; based on patent $\mathrm{WO} / 2014 / 193722)^{86}$ and anti-DNP ${ }^{87}$ (Supplemental Table 1). Single point mutation E430G or E345K was introduced in the heavy chain expression vectors either by PCR-mediated site directed mutagenesis or by gene synthesis (IDT). Antibody amino acids are numbered according to EU nomenclature ${ }^{88}$. After expression, IgG1, IgG2 and IgG4 antibodies were isolated from cell supernatant using a HiTrap protein A column (Cytiva, GE Healthcare). IgG3 antibodies were isolated using a HiTrap Protein G High Performance column (Cytiva, GE Healthcare). Antibodies were dialyzed overnight in PBS and filter-sterilized though $0.22 \mu \mathrm{m}$ Spin-X filters. Antibodies were analyzed by size exclusion chromatography (SEC) (Cytiva, GE Healthcare) and separated for monomeric fraction in case aggregation levels were $>5 \%$. Antibody concentration was determined by measurement of the absorbance at $280 \mathrm{~nm}$ and antibodies were stored at $-20^{\circ} \mathrm{C}$. 


\section{IgG and complement binding to DNP-coated beads}

Magnetic Dynabeads M-270 Streptavidin (Invitrogen) ( 6-7 x $10^{5}$ beads per sample) were washed in PBS-TH (PBS, pH 7.4, 0.05\% (v/v) Tween, 0.5\% human serum albumin (HSA)) and incubated with 0.003 or $1 \mu \mathrm{g} / \mathrm{ml}$ biotinylated 2,4-dinitrophenol (DNP-PEG2GSGSGSGK(Biotin)-NH2; 1186 Da; synthesized by Pepscan Therapeutics B.V., the Netherlands) in $0.1 \mathrm{ml} /$ sample PBS-TH for 30 minutes at $4^{\circ} \mathrm{C}$, shaking $( \pm 700 \mathrm{rpm})$. Next, DNPcoated beads were washed once in PBS-TH and incubated in $0.05 \mathrm{ml} / \mathrm{sample}$ PBS-TH with 20 $\mathrm{nM}$ anti-DNP IgG or a 3-fold serial dilution of anti-DNP IgG (starting from $90 \mathrm{nM}$ ) for 30 minutes at $4^{\circ} \mathrm{C}$, shaking $( \pm 700 \mathrm{rpm})$. Subsequent incubations mentioned below were performed in $0.025 \mathrm{ml} / \mathrm{sample}$ PBS-TH for 30 minutes at $4^{\circ} \mathrm{C}$, shaking $( \pm 700 \mathrm{rpm})$, unless otherwise stated. After each incubation, beads were washed three times with PBS-TH or VBS-TH (Veronal Buffered Saline pH 7.4, $0.25 \mathrm{mM} \mathrm{MgCl}_{2}, 0.5 \mathrm{mM} \mathrm{CaCl}_{2}, 0.05 \%$ (v/v) Tween, $0.5 \%$ HSA) dependent on the buffer used in the subsequent incubation step.

For detection of IgG binding, beads were incubated with $1 \mu \mathrm{g} / \mathrm{ml}$ goat anti-human kappaAlexaFluor647 (Southern Biotech, 2060-31). Next, beads were washed and fixed in 0.15 $\mathrm{ml} /$ sample $1 \%$ paraformaldehyde in PBS-TH.

For C1q binding experiments, beads were incubated in $0.025 \mathrm{ml} / \mathrm{sample} \mathrm{VBS-TH}$ with a 3-fold serial dilution (starting at $10 \mathrm{nM}$ ) of $\mathrm{C} 1$ or $\mathrm{C} 1 \mathrm{q}$ for 30 minutes at $37^{\circ} \mathrm{C}$, shaking $( \pm 700 \mathrm{rpm})$. To determine binding of 'C1-EDTA', $\mathrm{C} 1$ was incubated in VBS-THE (VBS-TH, $10 \mathrm{mM}$ EDTA) instead. To study the effect of C1-INH and EDTA on C1q binding, beads were first incubated with $0.025 \mathrm{ml} /$ sample $3 \mathrm{nM} \mathrm{C1}$ and then with $0.025 \mathrm{ml} /$ sample VBS-THE or 0.025 $\mathrm{ml} /$ sample $200 \mathrm{nM} \mathrm{C1}-\mathrm{INH}$ in VBS-TH for 30 minutes at $37^{\circ} \mathrm{C}$, shaking $( \pm 700 \mathrm{rpm})$. For C1q detection, beads were incubated with $5 \mu \mathrm{g} / \mathrm{ml}$ FITC-conjugated rabbit anti-human C1q (Dako, F0254).

To determine IgG, C1q and C3b deposition to beads in human serum, DNP-coated beads ( 6$7 \times 10^{5}$ beads per sample) were incubated in $0.05 \mathrm{ml} /$ sample VBS-TH with $20 \mathrm{nM}$ anti-DNP $\mathrm{IgG}$ and a 3 -fold serial dilution of $\Delta \mathrm{IgG} \Delta \mathrm{IgM}$ serum (starting from $10 \%$ ) for 30 minutes at $37^{\circ} \mathrm{C}$, shaking $( \pm 700 \mathrm{rpm})$. Otherwise, DNP-coated beads were incubated in VBS-TH with a 3-fold serial dilution of anti-DNP IgG (starting from $90 \mathrm{nM}$ ) and $1 \% \Delta \operatorname{IgG} \Delta \operatorname{IgM}$ serum for 30 minutes at $37^{\circ} \mathrm{C}$, shaking $( \pm 700 \mathrm{rpm})$.

For IgG, C1q and C3b detection, beads were washed and incubated in $0.025 \mathrm{ml} / \mathrm{sample} \mathrm{PBS}-$ $\mathrm{TH}$ with a detection antibody for either IgG, $\mathrm{C} 1 \mathrm{q}$ or $\mathrm{C} 3 \mathrm{~b}$ (1:300 FITC-conjugated goat anti-C3 IgG, De Beer Medicals, 1100). After incubation with detection antibodies, bead samples were washed and fixed in $0.15 \mathrm{ml} /$ sample $1 \%$ paraformaldehyde in PBS-TH and binding of IgG, $\mathrm{C} 1 \mathrm{q}$ or $\mathrm{C} 3 \mathrm{~b}$ to the beads was determined by flow cytometry (BD FACSVerse). Data were analyzed based on single bead population using FlowJo software and presented as Fluorescence Intensity (FI) means \pm SD or geometric means \pm SD of at least three independent experiments.

\section{Western blotting}

To determine binding of different forms of $\mathrm{C} 1$ to DNP-beads by western blotting, the amount of beads (and incubation volumes) were scaled up 4-fold ( 24-28 x $10^{5}$ beads/sample). Magnetic Dynabeads M-270 were successively incubated with $1 \mu \mathrm{g} / \mathrm{ml}$ DNP-biotin, $20 \mathrm{nM}$ anti-DNP IgG and $3 \mathrm{nM} \mathrm{C1q/C1/C1-EDTA,} \mathrm{as} \mathrm{described} \mathrm{above.} \mathrm{Next,} \mathrm{beads} \mathrm{were} \mathrm{washed} \mathrm{in}$ 
VBS-TH and boiled in $50 \mu \mathrm{L}$ sample buffer $(0.5 \mathrm{M}$ Tris-HCl, 2\% (w/v) SDS, 20\% (v/v) glycerol, $0.1 \%(\mathrm{w} / \mathrm{v})$ bromophenol blue, $\mathrm{pH}$ 7) with $25 \mathrm{mg} / \mathrm{ml}$ dithiothreitol (DTT) for 5 minutes at $95^{\circ} \mathrm{C}$. Beads were pelleted and $10 \mu \mathrm{L}$ of the sample supernatant was run on a $10 \%$ SDS-PAGE gel and subsequently transferred to a PVDF membrane (Trans-Blot Turbo Transfer System, Bio-Rad). Membranes were blocked with 4\% dried skim milk (ELK, Campina) in PBS-T (PBS with $0.05 \%$ Tween) for 1 hour at $37^{\circ} \mathrm{C}$. To detect $\mathrm{C} 1 \mathrm{q}$, membranes were incubated for 45 minutes in 1\% dried skim milk in PBS-T with rabbit anti-human C1q (1:300, Dako, A0136) and HRP-conjugated goat anti-rabbit IgG (1:10.000, Southern Biotech, 4030-05). Blots were washed between the successive antibody incubations.

To determine the removal of $\mathrm{C} 1 \mathrm{r}$ and $\mathrm{C} 1 \mathrm{~s}$ from bead-bound $\mathrm{C} 1$ by $\mathrm{C} 1-\mathrm{INH}$ by western blotting, the amount of beads (and incubation volumes) were scaled up 3-fold $\left(\sim 18-21 \times 10^{5}\right.$ beads/sample). Magnetic Dynabeads M-270 were successively incubated with $1 \mu \mathrm{g} / \mathrm{ml} \mathrm{DNP}-$ biotin and $20 \mathrm{nM}$ anti-DNP IgG, as described above. Next, beads were incubated with $1 \mathrm{nM}$ $\mathrm{C} 1$ in VBS-T (Veronal Buffered Saline pH 7.4, $0.25 \mathrm{mM} \mathrm{MgCl}_{2}, 0.5 \mathrm{mM} \mathrm{CaCl}_{2}, 0.05 \%$ (v/v) Tween) for 30 minutes at $37^{\circ} \mathrm{C}$, shaking. After washing, beads were incubated with $200 \mathrm{nM}$ $\mathrm{C} 1-\mathrm{INH}$ or a VBS-T buffer control for 30 minutes at $37^{\circ} \mathrm{C}$, shaking. Next, beads were pelleted and supernatant was collected and mixed 1:1 with 2x sample buffer containing $50 \mathrm{mg} / \mathrm{ml}$ DTT for 5 minutes at $95^{\circ} \mathrm{C}$. Next, $10 \mu \mathrm{L}$ samples were run on a $10 \%$ SDS-PAGE gel, transferred to a PVDF membrane and membranes were blocked, as described above. To detect C1r, C1s, C1INH or C1q, the membrane was incubated in PBS-T with 1\% ELK for 45 minutes with either goat anti-human C1r (1:300, R\&D Systems, AF1807), sheep anti-human C1s (1:300, R\&D Systems, AF2060), rabbit anti-C1-INH (1 $\mu \mathrm{g} / \mathrm{mL}$, Sino Biologicals, 10995-R018) or rabbit anti-human C1q (1:300), respectively. After washing, membranes were incubated 1:10.000 for 45 minutes with HRP-conjugated antibodies, either donkey anti-goat IgG (Southern Biotech, 6425-05), rabbit anti-sheep IgG (Southern Biotech, 6425-05) or goat anti-rabbit IgG. Membranes were developed using Enhanced Chemiluminesence (ECL, Cytiva, GE Healthcare).

\section{IgG and complement binding to $S$. aureus}

Depending on the experiment, $S$. aureus Wood46 (with low expression of staphylococcal protein A (Spa)) or S. aureus Newman $\triangle s p a / s b i$ (knock-out of Protein A and the second immunoglobulin-binding protein (Sbi)) ${ }^{89}$ was or was not fluorescently labelled by transformation with a GFP-expressing plasmid ${ }^{90}$. Bacteria were grown until log phase in Todd Hewitt Broth medium, washed and frozen at $-20^{\circ} \mathrm{C}$ until use. To prepare samples, bacteria were thawed and diluted to $\mathrm{OD}=0.1$ in RPMI-H (RPMI, $0.05 \%$ HSA). All subsequent incubations mentioned below were performed in RPMI-H at $4^{\circ} \mathrm{C}$, shaking $( \pm 700 \mathrm{rpm})$, unless stated otherwise. After each incubation, bacteria were washed once in RPMI-H by centrifugation.

For detection of $\mathrm{IgG}$ binding, $0.025 \mathrm{ml}$ bacteria was incubated with $0.025 \mathrm{ml} 3$-fold serial dilution anti-WTA IgG (starting from $90 \mathrm{nM}$, final concentration). Next, bacteria were incubated in $0.025 \mathrm{ml} / \mathrm{sample}$ RPMI-H with $1 \mu \mathrm{g} / \mathrm{ml}$ goat anti-human kappa-AlexaFluor647. For C1q binding experiments, $0.025 \mathrm{ml}$ bacteria was incubated with $0.025 \mathrm{ml} 50 \mathrm{nM}$ anti-WTA IgG (final concentration). Bacteria were next incubated in $0.025 \mathrm{ml} / \mathrm{sample}$ RPMI-H with a 3fold serial dilution of $\mathrm{C} 1$ or $\mathrm{C} 1 \mathrm{q}$ (starting at $30 \mathrm{nM}$ ) for 30 minutes at $37^{\circ} \mathrm{C}$, shaking $( \pm 700$ rpm). To determine binding of 'C1-EDTA', $\mathrm{C} 1$ was incubated in RPMI-HE (RPMI-H, $10 \mathrm{mM}$ 
EDTA) instead. For C1q detection, bacteria were incubated with $5 \mu \mathrm{g} / \mathrm{ml}$ FITC-conjugated rabbit anti-human C1q.

To determine $\mathrm{IgG}, \mathrm{C} 1 \mathrm{q}$ and $\mathrm{C} 3 \mathrm{~b}$ binding to bacteria in serum, $0.050 \mathrm{ml}$ bacteria were mixed with $0.025 \mathrm{ml} 3$-fold serial dilution anti-WTA $\operatorname{IgG}$ (starting from $90 \mathrm{nM}$, final concentration) and $0.025 \mathrm{ml} 1 \%$ (IgG or $\mathrm{C} 1 \mathrm{q}$ detection) or $5 \%$ (C3b detection) $\Delta \operatorname{IgG} \Delta \operatorname{IgM}$ serum (final concentration) and incubated 30 minutes at $37^{\circ} \mathrm{C}$, shaking $( \pm 700 \mathrm{rpm})$. For IgG, C1q or C3b detection bacteria were next incubated with detection antibody for $\mathrm{IgG}, \mathrm{C} 1 \mathrm{q}$ or $\mathrm{C} 3 \mathrm{~b}(1: 300$ FITC-conjugated goat anti-C3 IgG).

To determine $\mathrm{C} 3 \mathrm{~b}$ deposition on bacteria in serum in the presence of $\mathrm{C} 1$-blocking molecules, $0.020 \mathrm{ml}$ bacteria were mixed with $0.030 \mathrm{ml}$ RPMI-H with a 3-fold serial dilution anti-WTA $\operatorname{IgG}$ (starting from $67 \mathrm{nM}$, final concentration), $1 \% \Delta \operatorname{IgG} \Delta \operatorname{IgM}$ serum (final concentration) and either monoclonal anti-C1q antibody (HB8327 a4b11 ${ }^{46}$, ATCC, $10 \mu \mathrm{g} / \mathrm{ml}$ final concentration) or BBK32 (kindly provided by Dr. Brandon Garcia, $10 \mu \mathrm{g} / \mathrm{ml}$ final concentration). Bacteria were incubated 20 minutes at $37^{\circ} \mathrm{C}$, shaking $( \pm 700 \mathrm{rpm})$. For $\mathrm{C} 3 \mathrm{~b}$ detection bacteria were next incubated with FITC-conjugated goat anti-C3 IgG (1:300).

After incubation with detection antibodies, bacteria were washed and fixed in $0.15 \mathrm{ml} / \mathrm{sample}$ $1 \%$ paraformaldehyde in RPMI-H and analyzed using flow cytometry (BD FACSVerse). Data were analyzed by FlowJo software and presented as Fluorescence Intensity (FI) means \pm SD or geometric means $\pm \mathrm{SD}$ of at least three independent experiments.

\section{Phagocytosis}

Human neutrophils were isolated from blood of healthy donors by the Ficoll-Histopaque gradient method ${ }^{91}$. Phagocytosis was performed in a round-bottom 96-well plate. GFP-labelled Wood46 bacteria $\left(20 \mu \mathrm{L}\right.$ of $3.75 \times 10^{7}$ cells $\left./ \mathrm{ml}\right)$ were mixed with 2 -fold serial dilutions of antiWTA IgG in RPMI-H or $1 \% \Delta \operatorname{IgG} \Delta \operatorname{IgM}$ serum $\left(20 \mu \mathrm{L}\right.$ volume) for 15 minutes at $37^{\circ} \mathrm{C}$ for opsonization. Subsequently, neutrophils $\left(10 \mu \mathrm{L}\right.$ of $7.5 \times 10^{6}$ cells $\left./ \mathrm{ml}\right)$ were added giving a 10:1 bacteria to cell ratio and incubated for 15 minutes at $37^{\circ} \mathrm{C}$ on a shaker $(750 \mathrm{rpm})$ in a final volume of $50 \mu \mathrm{L}$. The reaction was stopped with $1 \%$ ice-cold paraformaldehyde and neutrophil-associated fluorescent bacteria were analyzed by flow cytometry by scatter gating on neutrophils. Phagocytosis was defined by the percentage of cells with a positive fluorescent signal (\% GFP-positive cells) of all neutrophils representing the overall phagocytosis efficacy.

\section{Surface plasmon resonance studies}

All surface plasmon resonance experiments were performed at $25^{\circ} \mathrm{C}$ using a Biacore $\mathrm{T} 200$ instrument (Cytiva, GE Healthcare) equipped with a flat carboxymethyldextran sensor chip (CMDP; Xantec). For DNP surface preparations, flow cells were activated for 7 minutes with a 1:1 mixture of $0.1 \mathrm{M}$ N-hydroxysuccinimide (NHS) and $0.1 \mathrm{M}$ (3-(N,Ndimethylamino)propyl-N-ethylcarbodiimide) at a flow rate of $10 \mu \mathrm{L} / \mathrm{min}$, followed by a 7 minute injection of $0.1 \mathrm{M}$ ethylenediamine in $0.1 \mathrm{M}$ sodium borate $\mathrm{pH}$ 8.5. DNP-NH-PEG(4)NHS (Iris Biotech) was reacted at a concentration of $5 \mathrm{mM}$ in PBS-T with the aminated surface to reach a coupling density of 250 reponse units (RU). As a reference surface, MeO-PEG(4)NHS (20 mM) was coupled to a density of 200 RU as described for the DNP surface. Binding analyses were performed in $\mathrm{HBST}^{++}(10 \mathrm{mM}$ HEPES, $150 \mathrm{mM} \mathrm{NaCl}, 0.5 \mathrm{mM} \mathrm{CaCl} 2,0.25 \mathrm{mM}$ $\mathrm{MgCl}_{2}, 0.005 \%$ Tween $20, \mathrm{pH} 7.4$ ) at a flow rate of $10 \mu \mathrm{L} / \mathrm{min}$ if not stated otherwise. Anti- 
DNP antibodies at concentrations of $4 \mathrm{nM}$ and $20 \mathrm{nM}$ were prepared in $\mathrm{HBST}^{++}$and injected for 120 seconds over the DNP and control surfaces. Subsequently, C1 or C1q (20 nM) were injected for 60 seconds to associate on top of the antibodies and dissociation was observed for 300 seconds. The surfaces were regenerated with a 60 second injection of $10 \mathrm{mM}$ glycine $\mathrm{pH}$ 2.0 at a flow rate of $20 \mu \mathrm{L} / \mathrm{min}$. Data were collected at a rate of $1 \mathrm{~Hz}$ and analyzed with Scrubber (version 2.0c; BioLogic). Reference signals from the control surface $(\mathrm{MeO})$ were subtracted from the DNP surface signals. The responses were normalized for analyte size contribution by dividing the data points of each analyte by the molecular weight of $\mathrm{C} 1$ (766 $\mathrm{kDa}$ ) or $\mathrm{Clq}(410 \mathrm{kDa})$, respectively, and multiplying them by 100 . The data were exported to Prism (version 8.1.2.; Graphpad).

\section{DNP-labelled liposomes}

DNP-labelled liposomes consisting of 1,2-dipalmitoyl-sn-glycero-3-phosphocholine (DPPC), 1,2-dipalmitoyl-sn-glycero-3-phosphoethanolamine (DPPE) and 1,2-dipalmitoyl-sn-glycero3-phosphoethanolamine-N-[6-[(2,4-dinitrophenyl)amino]hexanoyl] (DNP-cap-DPPE) were used to generate supported lipid bilayers ( $\mathrm{SLBs}$ ) on mica and $\mathrm{SiO}_{2}$ substrates. The lipids were purchased from Avanti Polar Lipids, mixed at a ratio of DPPC:DPPE:DNP-cap-DPPE = 90:5:5 (molar ratio), and dissolved in a 2:1 mixture of chloroform and methanol. After the solvents were rotary-evaporated for 30 minutes, the lipids were again dissolved in chloroform, which was then rotary-evaporated for 30 minutes. Drying was completed at a high vacuum pump for 2 hours. The lipids were dissolved in $500 \mu \mathrm{L}$ Milli-Q $\mathrm{H}_{2} \mathrm{O}$ while immersed in a water bath at $60^{\circ} \mathrm{C}$, flooded with argon, and sonicated for 3 minutes at $60^{\circ} \mathrm{C}$ to create small unilamellar vesicles. These were diluted to $2 \mathrm{mg} / \mathrm{ml}$ in buffer \#1 (10 mM HEPES, $150 \mathrm{mM} \mathrm{NaCl}, 2 \mathrm{mM}$ $\mathrm{CaCl}_{2}, \mathrm{pH}$ 7.4) and frozen for storage using liquid $\mathrm{N}_{2}$.

\section{High-speed atomic force microscopy}

HS-AFM ${ }^{92,93}$ (RIBM, Japan) was conducted in tapping mode at RT in buffer, with free amplitudes of $1.5-2.5 \mathrm{~nm}$ and amplitude set points larger than $90 \%$. Silicon nitride cantilevers with electron-beam deposited tips (USC-F1.2-k0.15, Nanoworld AG), nominal spring constants of $0.15 \mathrm{~N} \mathrm{~m}^{-1}$, resonance frequencies around $500 \mathrm{kHz}$, and a quality factor of approx. 2 in liquids were used. Imaging was performed in buffer \#1. All IgGs were diluted and incubated in the same buffer.

DNP-labelled supported lipid bilayers for HS-AFM were prepared on muscovite mica. The liposomes were incubated on the freshly cleaved surface $(500 \mu \mathrm{g} / \mathrm{ml}$ in buffer \#1), placed in a humidity chamber to prevent evaporation, and heated to $60{ }^{\circ} \mathrm{C}$ for 30 minutes. Then the temperature was gradually cooled down to RT within 30 minutes, followed by exchanging the solution with buffer \#1. After 10 minutes of equilibration at RT and 15 more buffer exchanges, the SLB was ready for imaging. In order to passivate any exposed mica, SLBs were incubated with 333 nM IgG1-b12 (irrelevant human IgG1 control antibody against HIV-1 gp120) ${ }^{94}$ for 10 minutes before the molecules of interest were added. Anti-DNP IgG1-RGY $(20 \mu \mathrm{g} / \mathrm{ml})$ was incubated for 5 minutes followed by several buffer exchanges to remove umbound IgGs from solution. After that, C1q $(20 \mu \mathrm{g} / \mathrm{ml})$ or $\mathrm{C} 1(15 \mu \mathrm{g} / \mathrm{ml})$ was added for 10 minutes, followed by another buffer exchange. In case of $\mathrm{C} 1 \mathrm{q}$, imaging was performed in the presence of $\mathrm{C} 1 \mathrm{q}$ in soluiton to enable rebinding during the experiment. 


\section{Statistical analysis}

Statistical analysis was performed with Prism software (version 8.0.1; GraphPad). All data are presented as means \pm SD or geometric means \pm SD from three independent experiments unless otherwise stated. 
Figure 1.

A

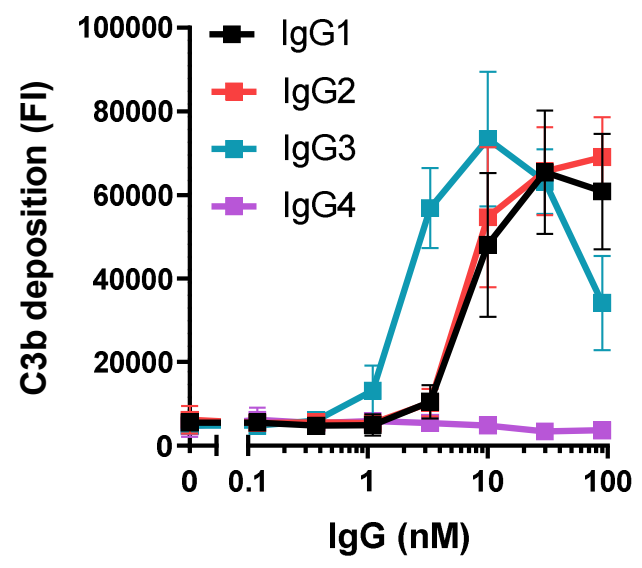

B

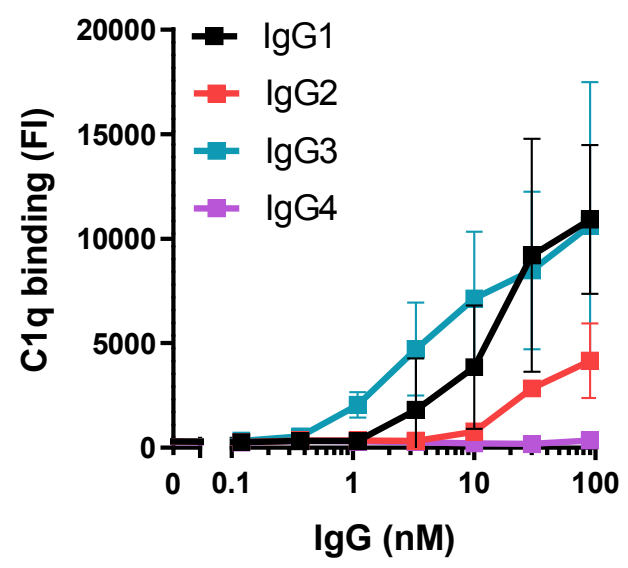

C

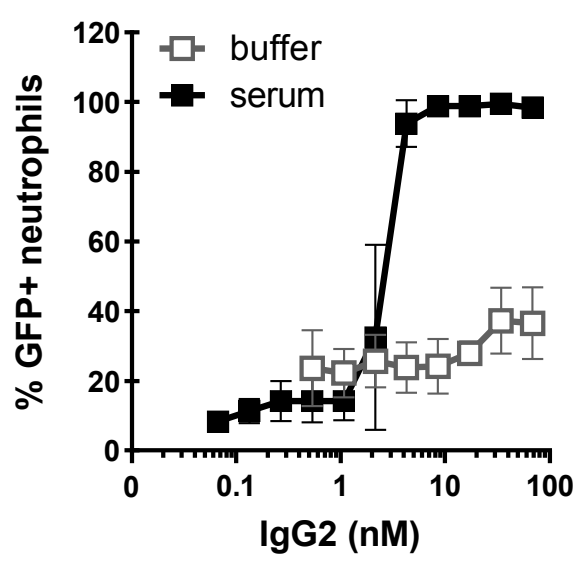

D

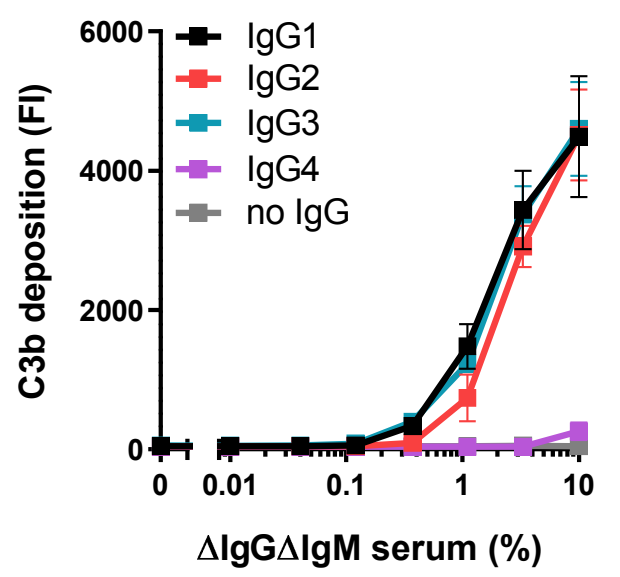

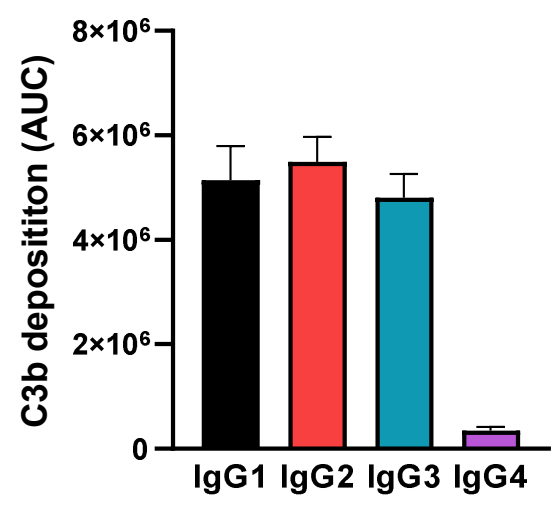

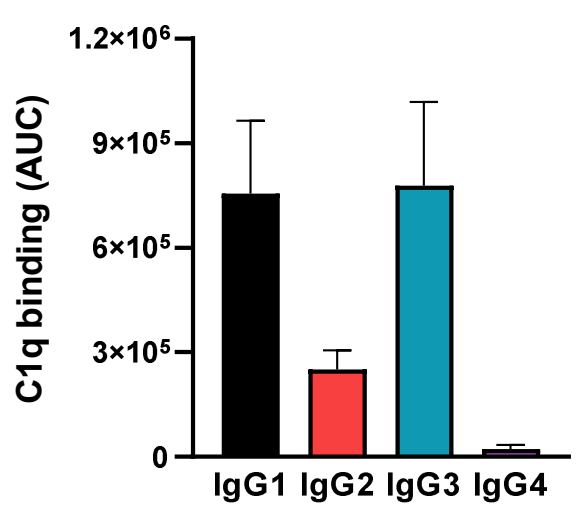

$\mathbf{E}$

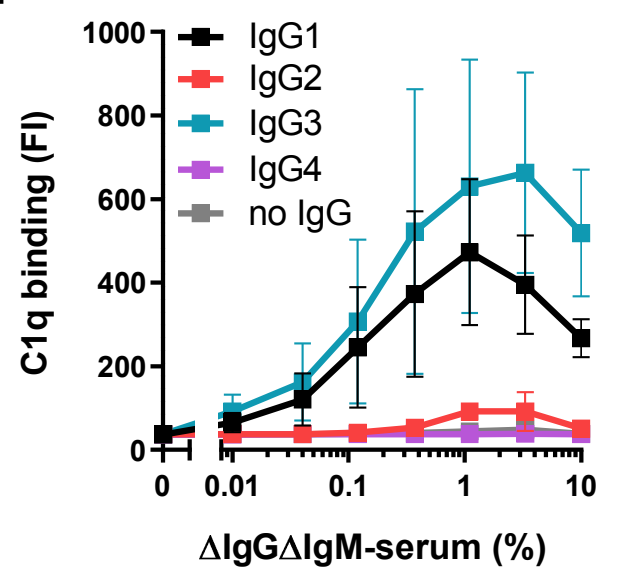


Figure 2.

A

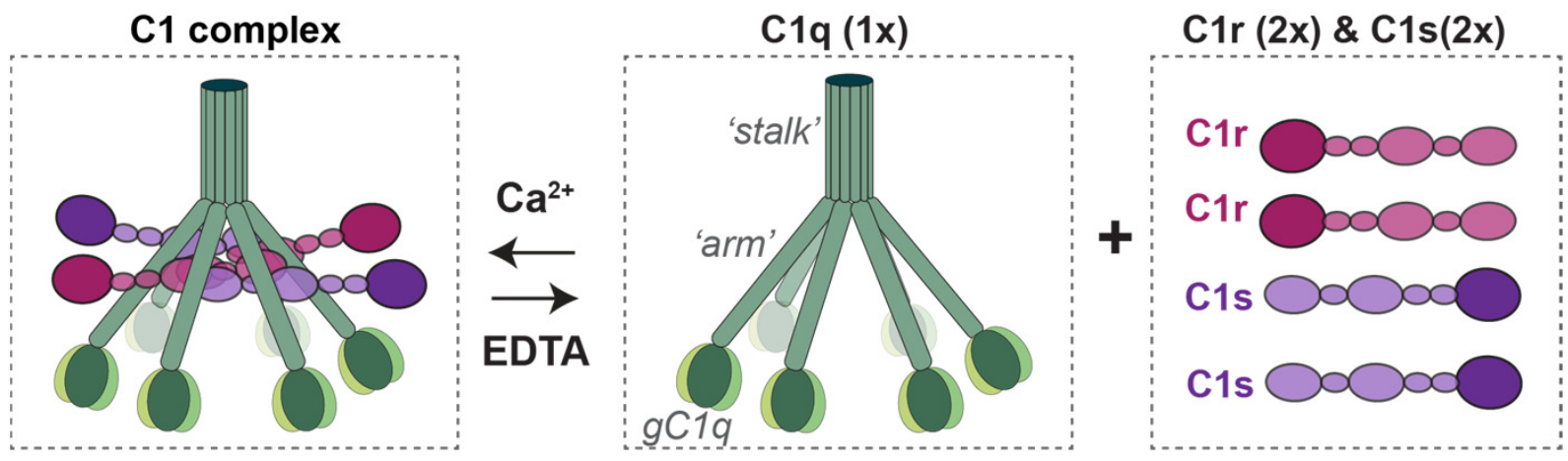

B

lgG1

IgG2

IgG3

IgG4
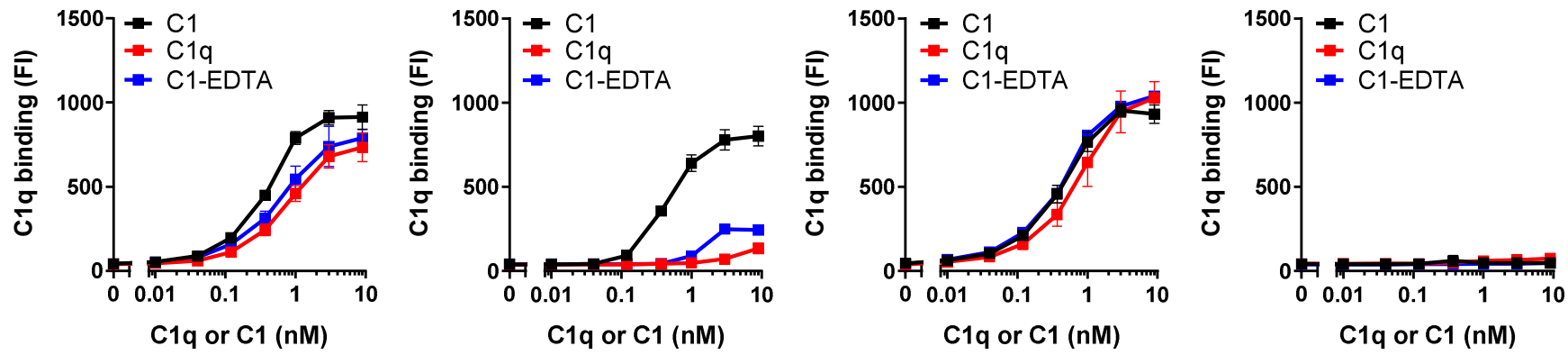

C

IgG3 (low DNP conc.)

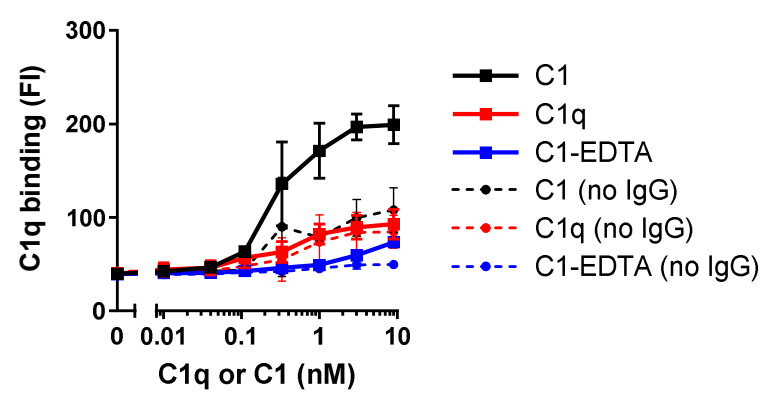




\section{Figure 3.}

A
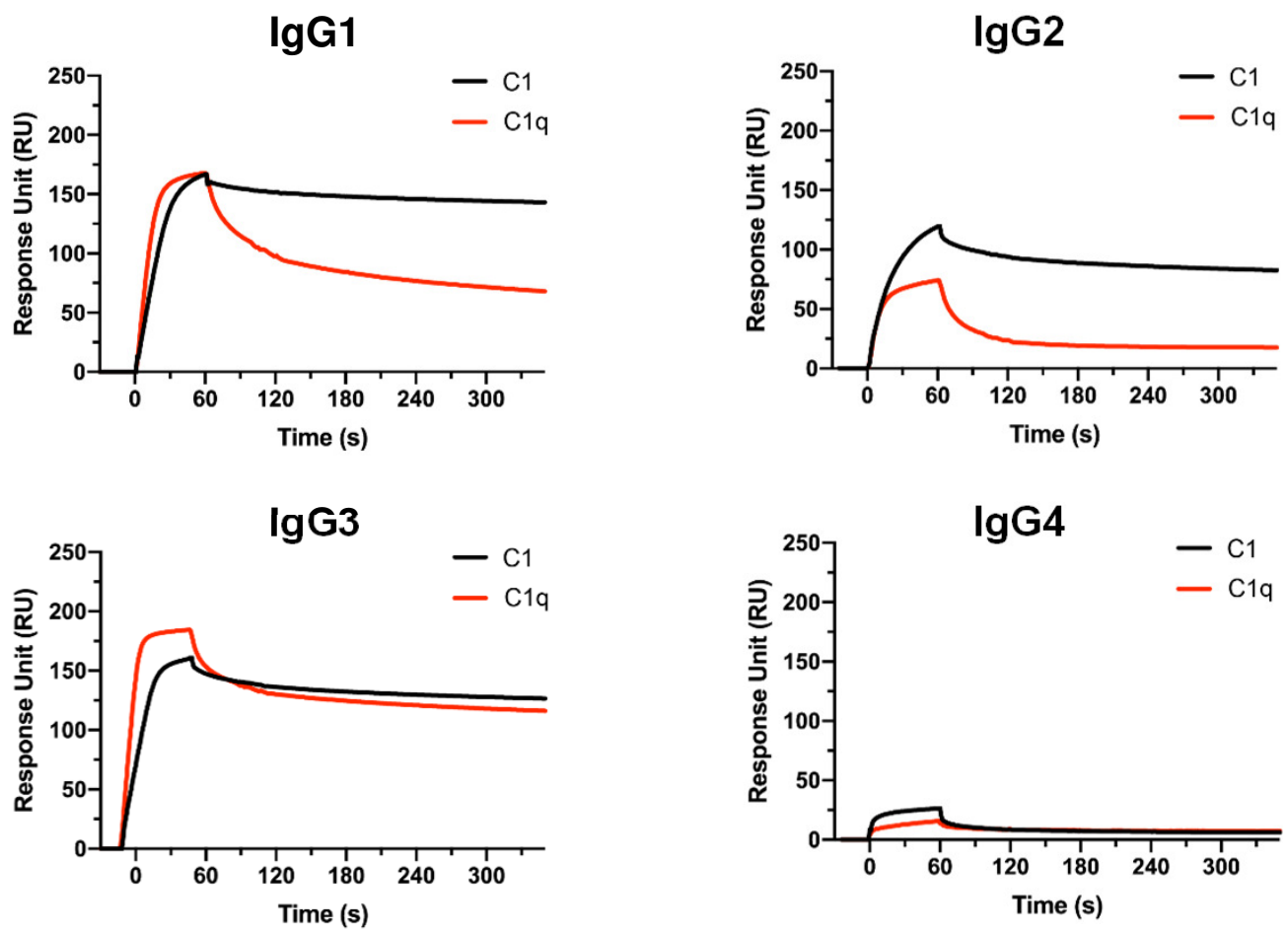

B

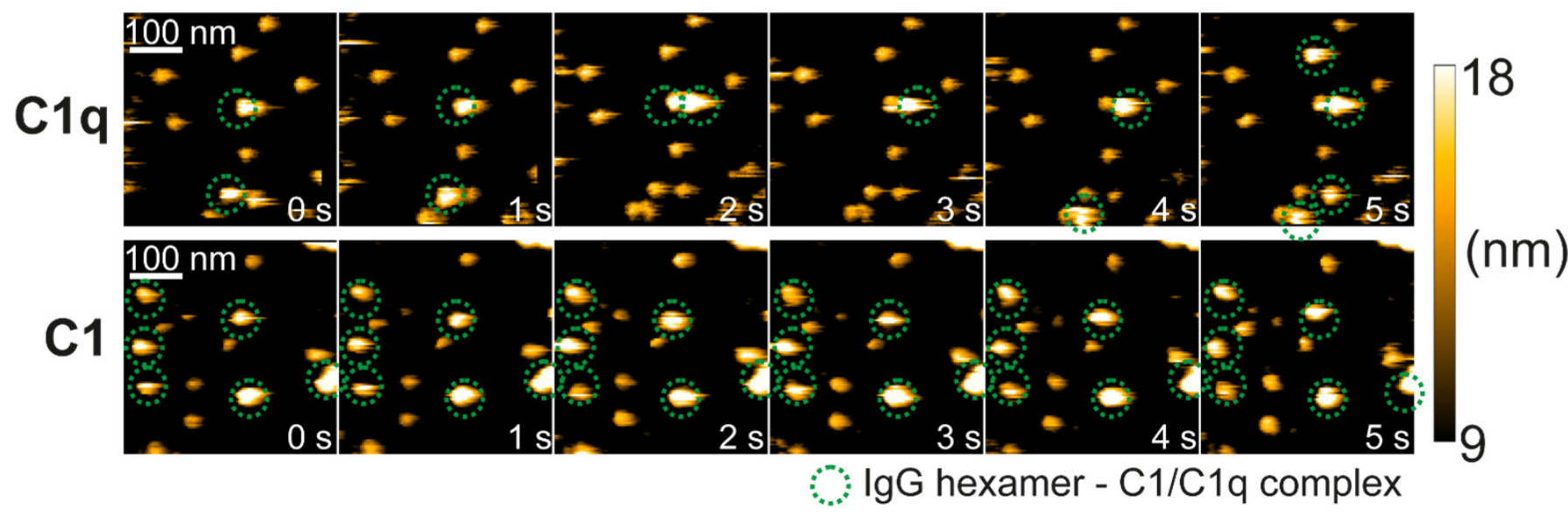

C

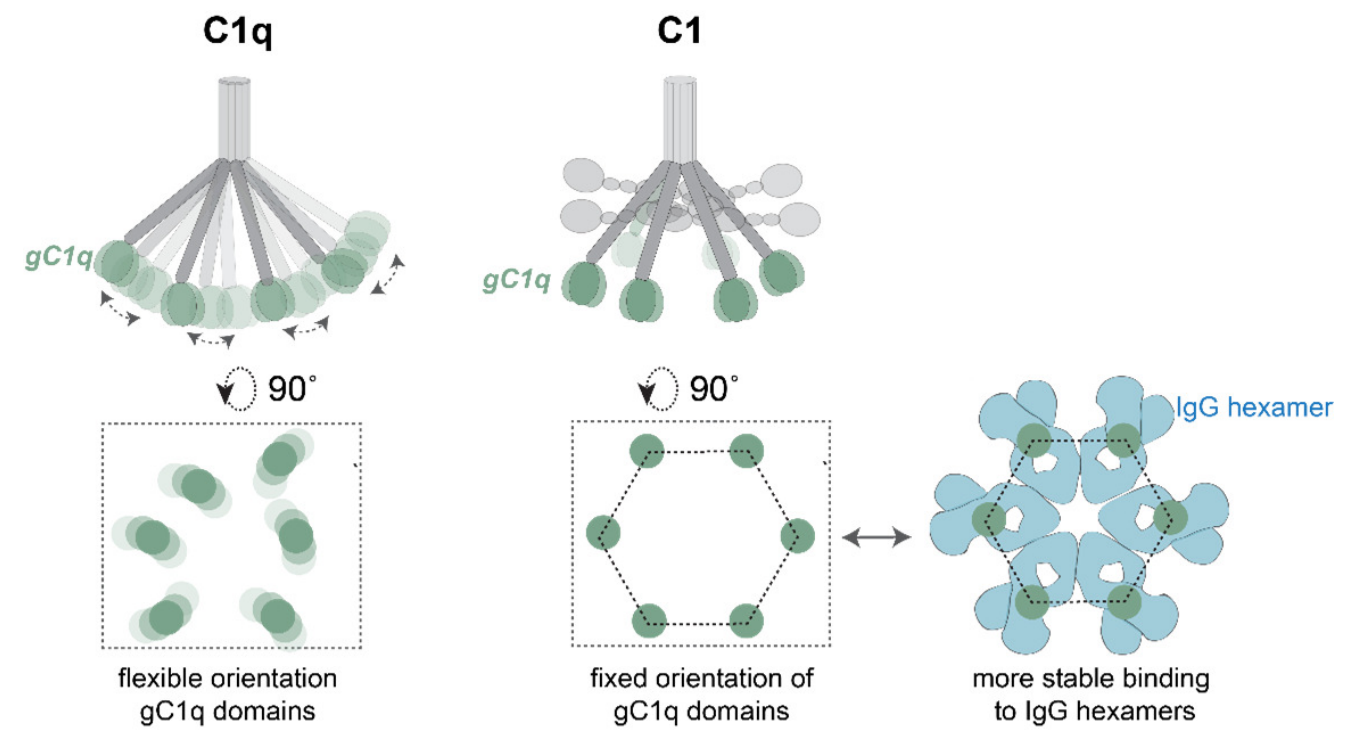


Figure 4.

A

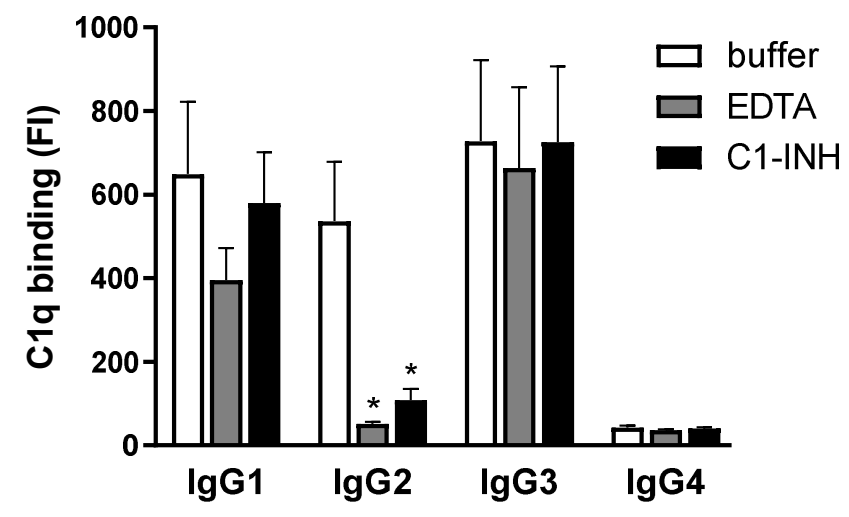

B

C1-INH removes proteases from C1q

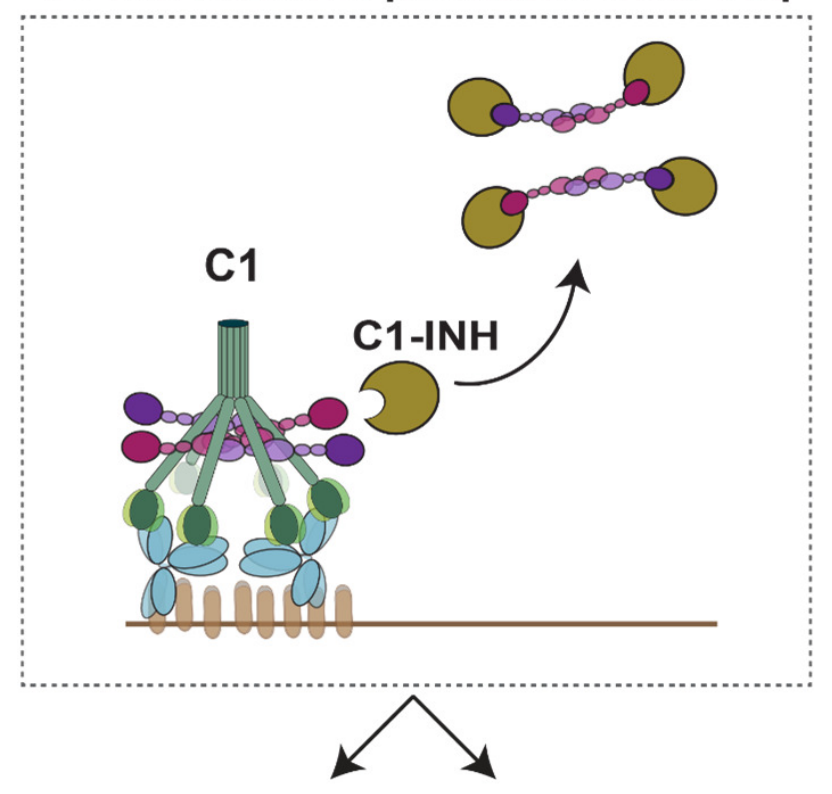

I. C1q dissociates or II. C1q remains

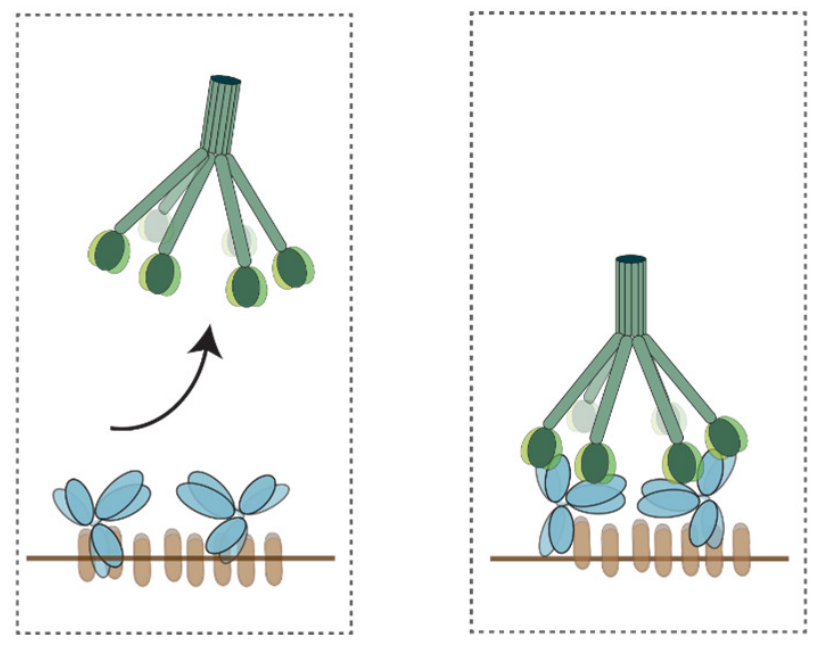


Figure 5.

A

\section{C1q}

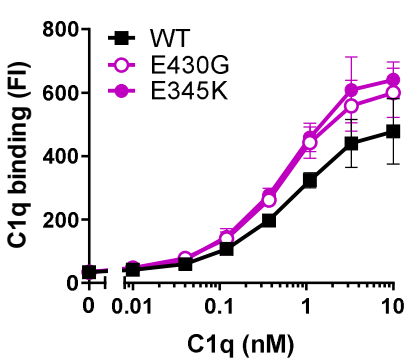

$\lg$ G2

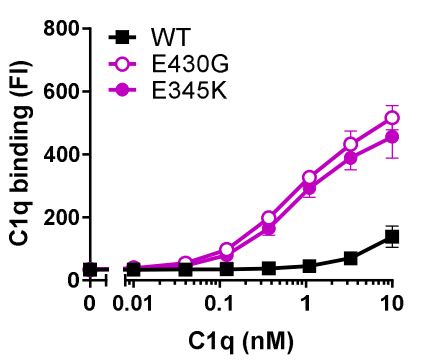

IgG3
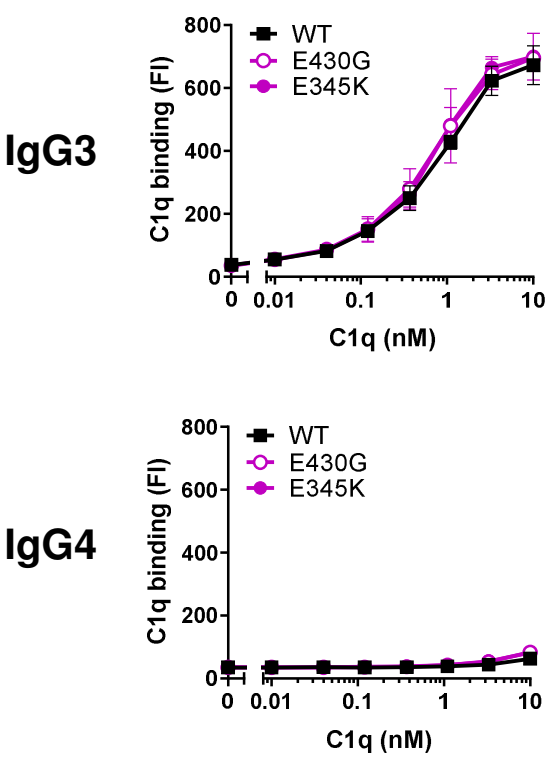

B

\section{C1}
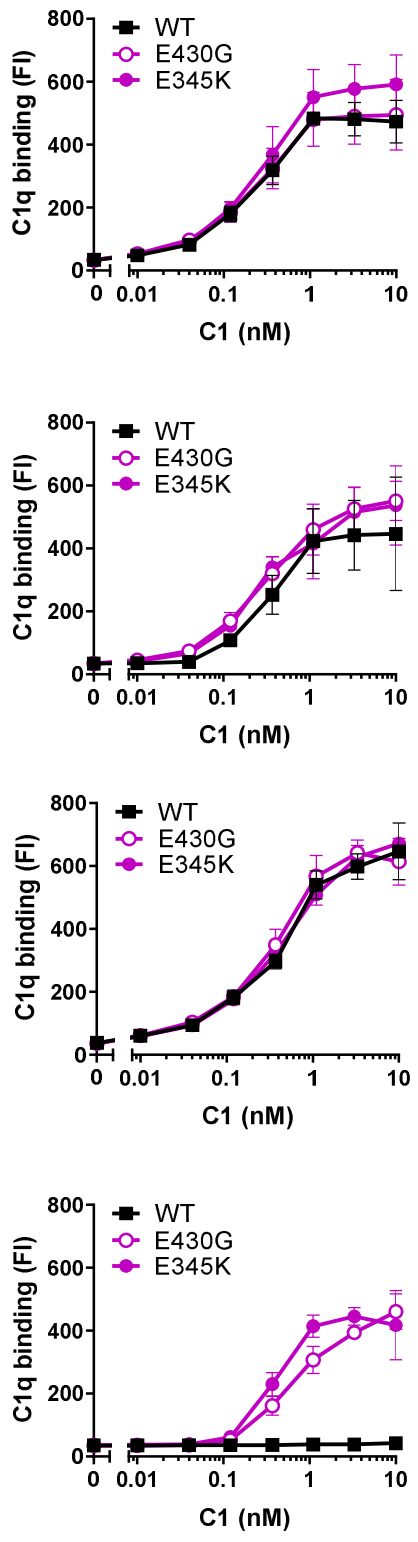

C

serum
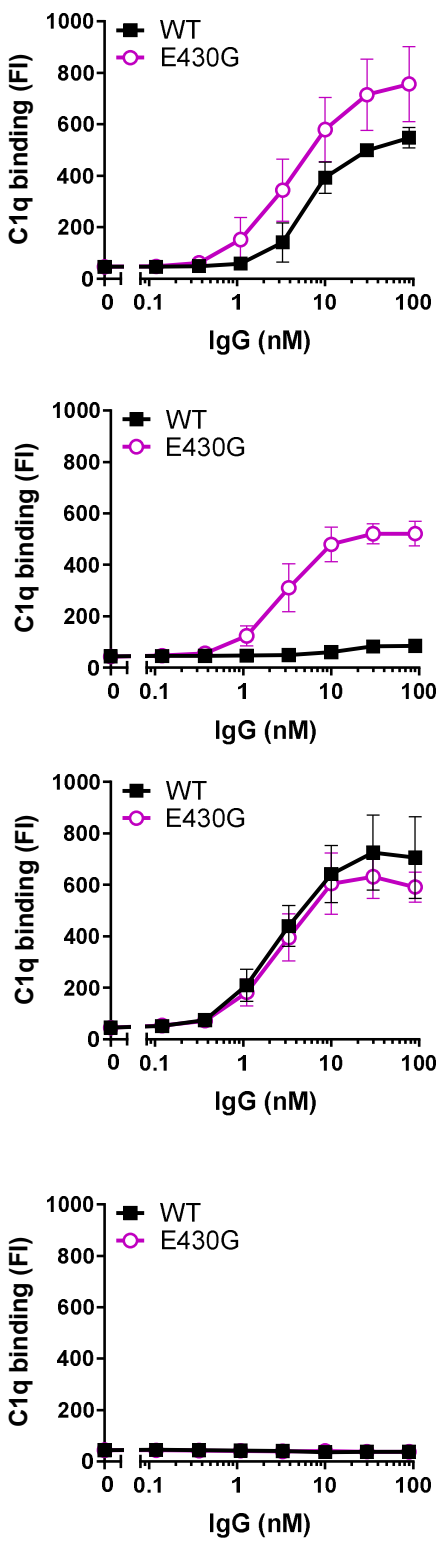
Figure 6.

A

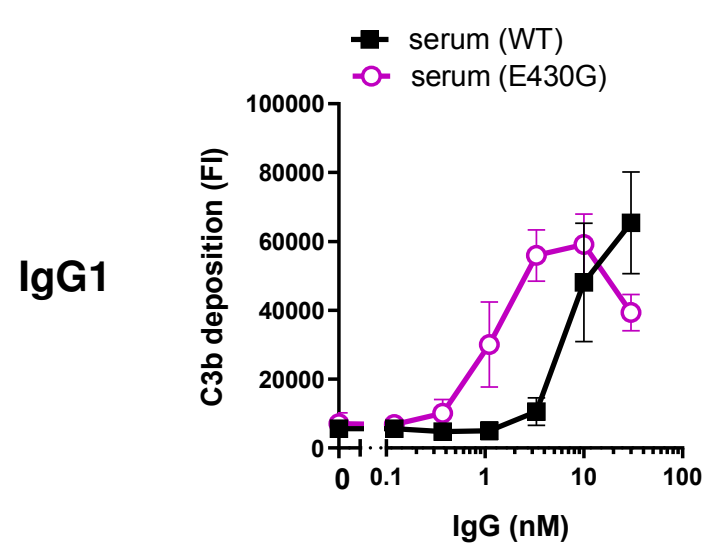

IgG2

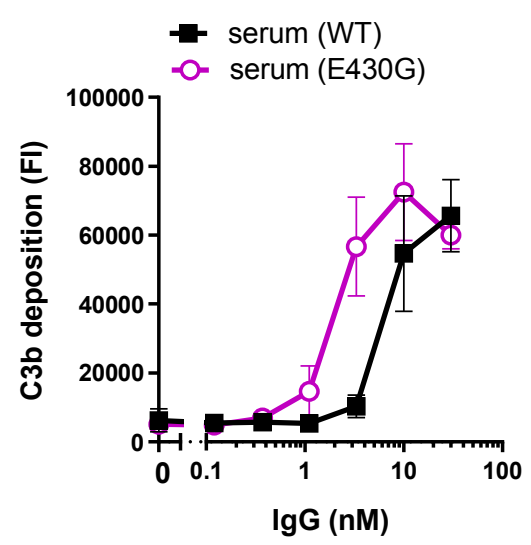

IgG3

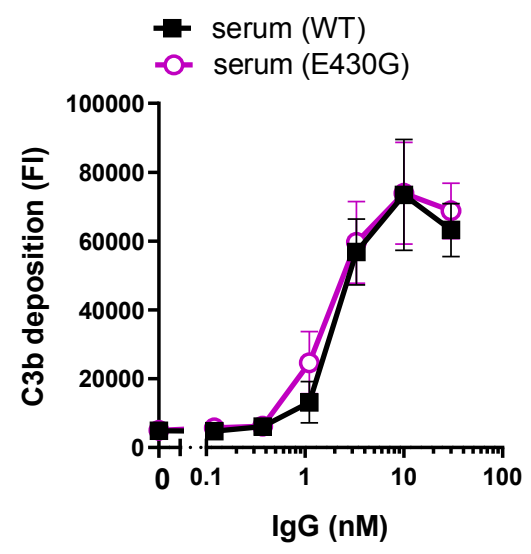

$\lg G 4$

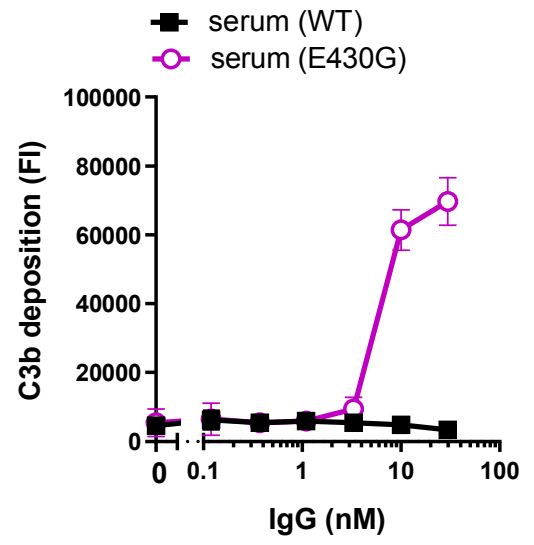

B
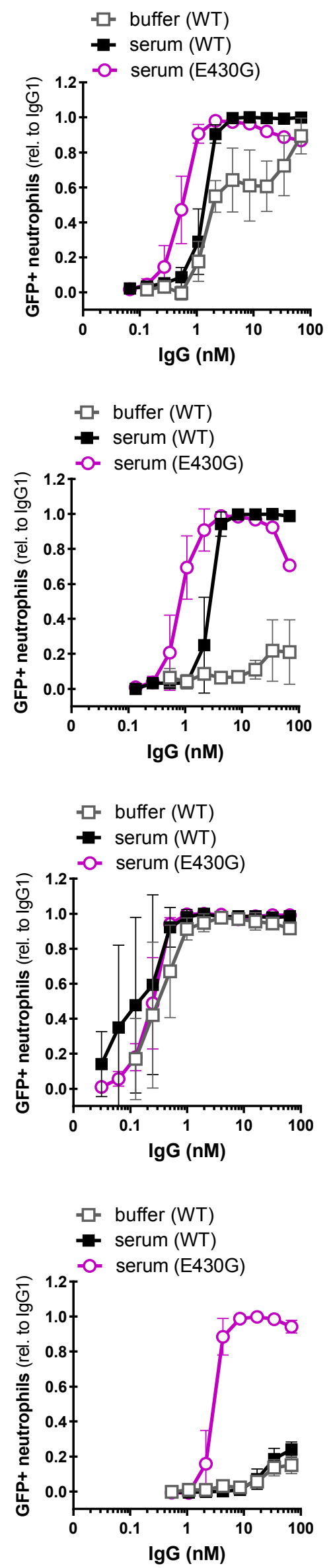